\author{
Federal Reserve Bank of Dallas \\ Globalization and Monetary Policy Institute \\ Working Paper No. 298 \\ https://www.dallasfed.org/ /media/documents/institute/wpapers/2017/0298.pdf
}

\title{
Domestic vs. International Welfare Gains from Trade*
}

\author{
Hakan Yilmazkuday \\ Florida International University
}

January 2017

\begin{abstract}
Using varieties of a rich model that considers sectoral heterogeneity and input-output linkages, this paper shows that the overall welfare gains of a region within a country can be decomposed into domestic versus international welfare gains from trade. Empirical results based on state-level data from the U.S. suggest that about 91 percent of the overall welfare gains of a state are due to domestic trade with other states, on average across alternative model specifications, with a range between 72 percent and 99 percent across states. When national-level data are used for the U.S., international welfare gains are shown to be almost identical to the those obtained by the aggregation of state-level results, suggesting that one can use the implications of a region-level analysis to have national-level results based on welfare gains from trade. We use this implication to propose an approximation to measure the domestic welfare gains from trade when domestic trade data are not available. Accordingly, using the implications of the model introduced, a Dispersion of Economic Activity Index (DEAI) is introduced that depends on internal distance and elasticity measures. It is empirically shown that DEAI can capture domestic welfare gains from trade within the U.S. when standard internal distance and elasticity measures in the literature are employed. Important policy suggestions follow.
\end{abstract}

JEL codes: F12, F14, R13

\footnotetext{
${ }^{*}$ Hakan Yilmazkuday, Department of Economics, Florida International University, $11200 \mathrm{SW} 8^{\text {th }}$ Street, Miami, FL 33199. 305-348-2316. hyilmazk@fiu.edu. The views in this paper are those of the authors and do not necessarily reflect the views of the Federal Reserve Bank of Dallas or the Federal Reserve System.
} 


\section{Introduction}

Domestic trade of a typical state in the U.S. is about five times its international trade, where about three quarters of this domestic trade is achieved with other states. It is implied that a typical state is about 20 percent open to international trade, while it is about 60 percent open to domestic trade. ${ }^{1}$ Since welfare gains from trade are directly connected to such openness measures as shown by Arkolakis, Costinot, and Rodríguez-Clare (2012) for a vast variety of models, the greater part of the welfare gains is implied to be through domestic trade. Nevertheless, since domestic trade data are not available for the majority of the countries, the existing literature has mostly focused on international welfare gains from trade that represent only a small portion of overall welfare gains.

Within this picture, this paper introduces a rich model considering sectoral heterogeneity as well as input-output linkages (as in studies such as by Levchenko and Zhang (2014), Caliendo and Parro (2015) and Ossa (2015)), where the unit of investigation is set as regions representing U.S. states. As standard in the literature, the corresponding welfare gains from trade are shown to be a function of expenditure shares and model parameters, where changes in expenditure shares are used to capture the changes in welfare in case of a hypothetical change in trade costs. The corresponding literature starting with Arkolakis, Costinot, and Rodríguez-Clare (2012) has focused on the hypothetical case of an autarky in the context of international trade. This paper follows this literature by having the same definition of international autarky while calculating the international welfare gains from trade.

The main contribution of this paper is achieved by considering an additional/alternative hypothetical case of autarky, namely domestic autarky, which is useful to calculate the domestic welfare gains from trade. In particular, domestic autarky is defined as the case in which a region still imports products internationally, but the domestic trade with other regions of the same country is shut down in this hypothetical case. It is shown that the overall percentage welfare gains from trade is the summation of domestic and international percentage welfare gains from trade.

Based on the significant difference between international and domestic openness measures of states in the U.S., the corresponding welfare analysis shows that about 91 percent of the overall percentage welfare gains of a state are due to domestic trade with other states, on average across alternative model specifications, with a range between 72 percent and 99 percent across states. When the same investigation is replicated by using data at the U.S. level, it is shown that the international welfare gains from trade measures are almost identical to the measures obtained by the aggregation of state-level results. Therefore, one

\footnotetext{
${ }^{1}$ See Table 1 and Section 4 of this paper regarding the details of the data used to obtain this information.
} 
can use the implications of a state-level analysis to have U.S. level results based on welfare gains from trade. We combine this result with other implications of the model in order to propose an approximation for domestic welfare gains from trade when domestic trade data are not available. Accordingly, we introduce a Dispersion of Economic Activity Index (DEAI) that can be calculated by using domestic distance measures (that can easily be obtained within a country) as well as other parameters such as trade elasticity and distance elasticity of trade costs. It is empirically shown that the proposed DEAI can capture the effects of domestic welfare gains from trade within the U.S. when great circle distance measures (that are calculated using latitudes and longitudes of states) are employed together with the elasticity measures borrowed from the literature.

Overall, this paper contributes to the existing literature by showing that (i) domestic welfare gains are much higher than international welfare gains from trade and (ii) when domestic trade data are not available, domestic welfare gains from trade can be approximated by a dispersion of economic activity index (DEAI). Regarding policy implications, when domestic trade data are not available, the calculated DEAI measures can be compared with the standard measures of international welfare gains from trade in order to evaluate policies toward integrating the regions of a country with the rest of the world. The importance of such integration policies can be better understood when certain extreme cases are considered. For instance, even when international trade costs are reduced to zero, due to their geographical location, landlocked regions will always pay higher prices (compared to coastal regions) for international products as shown in studies such as by Van Leemput (2016). This is similar to the findings in Limao and Venables (2001) or Irwin and Terviö (2002) who have shown that international trade costs are higher for landlocked countries. Therefore, independent of the international trade policy, landlocked states will always have relatively lower international expenditure shares and thus relatively lower international welfare gains from trade.

Within this picture, one optimal policy may be toward reducing such redistributive effects of landlockedness across regions of a country regarding their international trade costs. Since domestic trade costs are highly related to transportation technologies/networks as well as infrastructure as advocated in several studies such as by Donaldson (2010), this may well be achieved within the U.S. by providing more federal government funding for landlocked states to be used for building infrastructure with the objective of minimizing trade costs to the corresponding (e.g., closest) international U.S. ports. Therefore, international trade policies should be evaluated not only based on the redistributive costs of welfare through distribution of earnings across workers (as in Stolper and Samuelson (1941)) but also based on the implications on the cost of living differences across regions. The latter is in line with studies such as by Deaton and Muellbauer (1980) or recently in the context of trade by 
Fajgelbaum and Khandelwal (2014) who show that different groups of people face alternative welfare gains from trade based on their income and consumption patterns. On top of these studies, this paper suggests that the distribution of economic activity within a country should also be considered by policy makers with the objective of reducing cost of living differences across regions through integrating landlocked regions with the rest of the world.

In the existing literature, the consideration of domestic integration is shown to be important to explain observed import shares, effects of economic integration agreements, relative income and price levels as well as the relationship between country size and income levels across countries (e.g., see Bergstrand, Larch, and Yotov (2015) and Ramondo, RodriguezClare, and Saborio-Rodriguez (2016)). Domestic integration through lowering domestic trade costs is also shown to result in substantial welfare gains, especially for poor regions (e.g., see Donaldson (2010), Tombe and Winter (2014), or Van Leemput (2016)). Nevertheless, none of these studies have compared the welfare gains from domestic versus international trade, where the former explains about 91 percent of the overall percentage welfare gains from trade within the U.S. in this paper. As also shown in this paper, such a distinction is important to understand the differences in welfare gains from trade across regions due to their geographical location within a country.

The rest of this paper is organized as follows. The next section introduces the economic environment. Section 3 derives the welfare gains from trade expressions. Section 4 introduces the data set and the corresponding descriptive statistics. Section 5 depicts the state-level welfare gains obtained by alternative specifications of the model introduced in Section 2 . Section 6 connects the state-level results to the U.S. level through appropriate aggregations as well as additional aggregate-level analyses. Section 7 discusses the policy implications of having domestic versus international welfare gains from trade. Section 8 concludes.

\section{Economic Environment}

Since Arkolakis, Costinot, and Rodríguez-Clare (2012) have shown that welfare gains from trade can be measured by simple expressions based on expenditure shares and certain parameters for a wide range of models, we consider an Armington (1969) type model in order to have an empirical motivation. In particular, we introduce a multi-region multi-sector model, where individuals supply labor to monopolistically-competitive firms in return for their wage income. Production is achieved by using both labor and intermediate inputs purchased from other sectors and regions, which allows us to consider input-output linkages as well as sectoral heterogeneity. 


\subsection{Individuals and Firms}

A typical individual in region $r$ maximizes utility given by:

$$
C_{r} \equiv \prod_{j}\left(\frac{\left(\sum_{i}\left(\beta_{r, i}^{j}\right)^{\frac{1}{\eta^{j}}}\left(C_{r, i}^{j}\right)^{\frac{\eta^{j}-1}{\eta^{j}}}\right)^{\frac{\eta^{j}}{\eta^{j}-1}}}{\beta_{r}^{j}}\right)^{\beta_{r}^{j}}
$$

where $C_{r, i}^{j}$ is consumption of variety $i$ of good $j$ produced in region $i ; \eta^{j}>1$ is the elasticity of substitution across varieties; $\beta_{r}^{j}$ and $\beta_{r, i}^{j}$ are taste parameters satisfying $\sum_{j} \beta_{r}^{j}=\sum_{i} \beta_{r, i}^{j}=$ 1. The individual receives both labor income $W_{r}$ (out of inelastically supplying unit labor endowment) and profit income $\Gamma_{r}$ (out of the profits made by the firm that the individual supplies labor to in region $r$ ):

$$
P_{r} C_{r}=\sum_{j} P_{r}^{j} C_{r}^{j}=\sum_{j} \sum_{i} P_{r, i}^{j} C_{r, i}^{j}=W_{r}+\Gamma_{r}
$$

where $P_{r}, P_{r}^{j}$ and $P_{r, i}^{j}$ are prices of $C_{r}, C_{r}^{j}$ and $C_{r, i}^{j}$, respectively. The optimal allocation of any given expenditure within each variety of goods yields the following demand function for $C_{r, i}^{j}$ :

$$
C_{r, i}^{j}=\beta_{r}^{j} \beta_{r, i}^{j}\left(P_{r, i}^{j}\right)^{-\eta^{j}}\left(P_{r}^{j}\right)^{\eta^{j}-1} P_{r} C_{r}
$$

where $P_{r}^{j} \equiv\left(\sum_{i} \beta_{r, i}^{j}\left(P_{r, i}^{j}\right)^{1-\eta^{j}}\right)^{\frac{1}{1-\eta^{j}}}$ and $P_{r}=\prod_{j}\left(P_{r}^{j}\right)^{\beta_{r}^{j}}$.

Each monopolistically-competitive firm in region $r$ produces variety $r$ of a good by using local labor and intermediate inputs according to the following production function:

$$
Y_{r}^{j}=A_{r}^{j}\left(\frac{L_{r}^{j}}{l^{j}}\right)^{l^{j}}\left(\frac{G_{r}^{j}}{g^{j}}\right)^{g^{j}}
$$

where $A_{r}^{j}$ represents good- and region-specific technology, $L_{r}^{j}$ represents labor used, $G_{r}^{j}$ represents the composite intermediate input, and finally, $l^{j}$ and $g^{j}\left(=1-l^{j}\right)$ represent goodspecific factor shares. The cost minimization problem of the firm results in the following marginal cost expression:

$$
Z_{r}^{j}=\frac{\left(W_{r}\right)^{l^{j}}\left(Q_{r}^{j}\right)^{g^{j}}}{A_{r}^{j}}
$$


where $Q_{r}^{j}$ is the price of $G_{r}^{j}$ that is further given by:

$$
G_{r}^{j} \equiv \prod_{k}\left(\frac{\left(\sum_{i}\left(\gamma_{r, i}^{j, k}\right)^{\frac{1}{\eta^{k}}}\left(G_{r, i}^{j, k}\right)^{\frac{\eta^{k}-1}{\eta^{k}}}\right)^{\frac{\eta^{k}}{\eta^{k}-1}}}{\gamma^{j, k}}\right)^{\gamma^{j, k}}
$$

where $G_{r, i}^{j, k}$ is the intermediate input of variety $i$ of good $k$ (which is produced in region $i$ ), $\gamma^{j, k}$ and $\gamma_{r, i}^{j, k}$ are technology parameters satisfying $\sum_{k} \gamma^{j, k}=\sum_{i} \gamma_{r, i}^{j, k}=1$. The optimal allocation of any given expenditure within each variety of goods yields the following demand function for $G_{r, i}^{j, k}$ :

$$
G_{r, i}^{j, k}=\gamma^{j, k} \gamma_{r, i}^{j, k}\left(P_{r, i}^{k}\right)^{-\eta^{k}}\left(Q_{r}^{j, k}\right)^{\eta^{k}-1} Q_{r}^{j} G_{r}^{j}
$$

where $P_{r, i}^{k}$ and $Q_{r}^{j, k}$ are prices of $G_{r, i}^{j, k}$ and $G_{r}^{j, k}$, respectively, satisfying $Q_{r}^{j, k} \equiv\left(\sum_{i} \gamma_{r, i}^{j, k}\left(P_{r, i}^{k}\right)^{1-\eta^{k}}\right)^{\frac{1}{1-\eta^{k}}}$ and $Q_{r}^{j}=\prod_{k}\left(Q_{r}^{j, k}\right)^{\gamma^{j, k}}$.

Since the firm sells its products as both final goods and intermediate inputs to all regions, the market clearing condition is implied as follows:

$$
Y_{r}^{j}=\sum_{i} \tau_{i, r}^{j} C_{i, r}^{j}+\sum_{i} \sum_{k} \tau_{i, r}^{j} G_{r, i}^{k, j}
$$

where $\tau_{i, r}^{j}>1$ represents gross iceberg trade costs. Using Equations 3 and 6, profit maximization problem results in the following optimal-price expression:

$$
P_{r, r}^{j}=\frac{\eta^{j} Z_{r}^{j}}{\eta^{j}-1}
$$

which is measured at the source. Accordingly, destination price at region $i$ is implied as $P_{i, r}^{j}=\tau_{i, r}^{j} P_{r, r}^{j}$, while total expenditure of region $i$ for good $j$ produced in region $r$ is implied as $P_{i, r}^{j} C_{i, r}^{j}=P_{r, r}^{j} \tau_{i, r}^{j} C_{i, r}^{j}=P_{r, r}^{j} Y_{i, r}^{j}$, with $Y_{i, r}^{j}$ representing the source quantity of good $j$ in region $r$ exported to region $i$. Hence, according to iceberg trade costs, it does not matter where the value (price times quantity) of trade is measured.

Since $l^{j}+g^{j}=1$, Equation 8 implies the following expression for gross profits:

$$
Y_{r}^{j} P_{r, r}^{j}=\left(\frac{\eta^{j}}{\eta^{j}-1}\right) Y_{r}^{j} Z_{r}^{j}
$$


which can be aggregated across regions to have:

$$
\frac{\sum_{r} Y_{r}^{j} P_{r, r}^{j}}{\sum_{r} Y_{r}^{j} Z_{r}^{j}}=\frac{\eta^{j}}{\eta^{j}-1}
$$

which is a useful expression to estimate $\eta^{j}$ 's when the corresponding production data are available as shown by Yilmazkuday (2012).

Per capita profits (that are equal across individuals supplying labor to this firm) are implied as follows:

$$
\Gamma_{r}=\frac{Y_{r}^{j} Z_{r}^{j}}{L_{r}^{j}\left(\eta^{j}-1\right)}=\frac{W_{r}}{l^{j}\left(\eta^{j}-1\right)}
$$

which are equalized across individuals in region $r$ (through the equalization of utilities) working in different sectors (e.g., $j$ and $k$ ) due to the mobility of labor within each region:

$$
\Gamma_{r}=\frac{W_{r}}{l^{j}\left(\eta^{j}-1\right)}=\frac{W_{r}}{l^{k}\left(\eta^{k}-1\right)}=\chi W_{r}
$$

which implies that total per capita expenditure (Equation 2) in region $r$ is given by $P_{r} C_{r}=$ $(1+\chi) W_{r}$.

\section{Welfare Gains from Trade}

We are interested in the change of utility that is given by:

$$
W G T_{r}=\frac{C_{r}}{C_{r}^{\prime}}=\frac{W_{r} P_{r}^{\prime}}{W_{r}^{\prime} P_{r}}
$$

where $C_{r}$ represents the current utility, while $C_{r}^{\prime}$ represents utility under a hypothetical case for investigation purposes; we will use the notation of $x^{\prime}$ to represent any variable $x$ in the hypothetical case from this point on.

We start with finding an expression for $P_{r}$ by using $P_{r}=\prod_{j}\left(P_{r}^{j}\right)^{\beta_{r}^{j}}$ and $Q_{r}^{j}=\prod_{k}\left(Q_{r}^{j, k}\right)^{\gamma^{j, k}}$ as well as Equations 3, 5, 6 and 8, which results in the following expression when $i=r$ :

$$
P_{r}=\prod_{j}\left(\left(\frac{\beta_{r}^{j} \beta_{r, r}^{j}}{\omega_{r, r}^{j}}\right)^{\frac{1}{1-\eta^{j}}} \frac{\tau_{r, r}^{j} \eta^{j}\left(W_{r}\right)^{l^{j}}\left(Q_{r}^{j}\right)^{g^{j}}}{A_{r}^{j}\left(\eta^{j}-1\right)}\right)^{\beta_{r}^{j}}
$$


which implies that

$$
\frac{P_{r}^{\prime}}{P_{r}}=\prod_{j}\left(\left(\frac{\omega_{r, r}^{j}}{\omega_{r, r}^{j \prime}}\right)^{\frac{1}{1-\eta^{j}}}\left(\frac{W_{r}^{\prime}}{W_{r}}\right)^{l^{j}}\left(\frac{Q_{r}^{j \prime}}{Q_{r}^{j}}\right)^{g^{j}}\right)^{\beta_{r}^{j}}
$$

where $\omega_{r, r}^{j}=\frac{P_{r, r}^{j} C_{r, r}^{j}}{P_{r} C_{r}}$ is the current home expenditure share of good $j$ in region $r$. In this expression, preferences of $\beta_{r}^{j}$ 's and $\beta_{r, r}^{j}$ 's, internal trade costs of $\tau_{r, r}^{j}$ 's, technology parameters of $A_{r}^{j}$ 's, and elasticities of $\eta^{j}$ 's are effectively cancelled out, since they are assumed to be the same between the current and hypothetical cases. Substituting this expression into Equation 11 results in the following expression after simple manipulations:

$$
W G T_{r}=\prod_{j}\left(\left(\frac{\omega_{r, r}^{j}}{\omega_{r, r}^{j !}}\right)^{\frac{1}{1-\eta^{j}}}\left(\frac{Q_{r}^{j \prime}}{Q_{r}^{j}} \frac{W_{r}}{W_{r}^{\prime}}\right)^{g^{j}}\right)^{\beta_{r}^{j}}
$$

where

$$
\left(\frac{Q_{r}^{j \prime}}{Q_{r}^{j}} \frac{W_{r}}{W_{r}^{\prime}}\right)=\prod_{k}\left(\left(\frac{\kappa_{r, r}^{j, k}}{\kappa_{r, r}^{j, k \prime}}\right)^{\frac{1}{1-\eta^{k}}}\left(\frac{Q_{r}^{k \prime}}{Q_{r}^{k}} \frac{W_{r}}{W_{r}^{\prime}}\right)^{g^{k}}\right)^{\gamma^{j, k}}
$$

corresponds to a system of equations that are log-linear in $\frac{Q_{r}^{j \prime}}{Q_{r}^{j}} \frac{W_{r}^{r}}{W_{r}^{\prime}}$ s that can be solved for each region $r$ individually after taking logs and representing everything in matrix format as $\mathbf{Q}=(\mathbf{I}-\mathbf{g})^{-\mathbf{1}} \mathbf{K v}$, where $\mathbf{Q}$ is a region- $r$ specific vector (of size $J \times 1$ ) consisting of $\log \left(\frac{Q_{r}^{j \prime}}{Q_{r}^{j}} \frac{W_{r}}{W_{r}^{\prime}}\right)$ 's, $\mathbf{I}$ is the identity matrix (of size $J \times J$ ), $\mathbf{g}$ is a matrix (of size $J \times J$ ) consisting of $g^{k} \gamma^{j, k}$ 's, $\mathbf{K}$ is a matrix (of size $J \times J$ ) consisting of $\log \left(\frac{\kappa_{r}^{j, k}}{\kappa_{r, r}^{j, k}}\right)^{\frac{\gamma^{j, k}}{1-\eta^{k}}}, \mathbf{s}, \mathbf{v}$ is a vector of ones (of size $J \times 1$ ), with $J$ representing the number of goods and $\kappa_{r, r}^{j, k}=\frac{P_{r, r}^{k} G_{r, r}^{j, k}}{Q_{r}^{j} G_{r}^{j}}$ representing the share of home intermediate inputs of good $k$ used in the production of good $j$.

For the calculation of Equation 12, one only needs information on the expenditure share of $\frac{\omega_{r, r}^{j}}{\omega_{r, r}^{j, r}}$ and $\frac{\kappa_{r}^{j, r}}{\kappa_{r, r}^{j, k}}$ as well the parameters of $\eta^{j}$ 's, $g^{j}$ 's, $\beta_{r}^{j}$ 's, and $\gamma^{j, k}$ 's. Within this picture, we do not need any information on either wages (of $W_{r}$ and $W_{r}^{\prime}$ ) or intermediate input prices (of $Q_{r}^{j}$ and $\left.Q_{r}^{j \prime}\right)$, since they are calculated according to Equation 13, where we only need information on $\kappa_{r, r}^{j, k}$ 's, $\kappa_{r, r}^{j, k}$ 's, $g^{k}$ 's and $\gamma^{j, k}$ 's. Therefore, we are not imposing any restrictions on the determination of wages across regions; i.e., labor can be mobile or immobile across regions of a country. Similarly, we do not impose any restrictions (across regions) on preferences of $\beta_{r}^{j}$ 's and $\beta_{r, r}^{j}$ 's or technology parameters of $A_{r}^{j}$ 's, either; i.e., preferences and technology can be mobile or immobile across regions of a country. We will talk more about these issues when we will connect our region-level analysis to the nation-level analysis below. 
In sum, we keep parameters the same between the current and hypothetical cases, the current expenditure shares of $\omega_{r, r}^{j}$ and $\kappa_{r, r}^{j, k}$ are given by the current data, and wages and intermediate-input prices are identified through these measures in Equation 13. Within this picture, the definition of expenditure shares in the hypothetical case $\left(\omega_{r, r}^{j \prime}\right.$ and $\left.\kappa_{r, r}^{j, k \prime}\right)$ plays an important role in the determination of welfare gains from trade, which we focus on next.

\subsection{Domestic versus International Welfare Gains from Trade}

While calculating the welfare gains from trade, we would like to distinguish between domestic and international imports, where the former is defined as imports coming from regions within the same country, while the latter is defined as imports coming from other countries. In order to keep things simple, we consider all international imports of a region as the products coming from region $F$ representing the combination of countries other than the domestic country. In terms of definitions, we use the phrase of home products to represent goods produced within the same region, domestic products to represent goods produced within the same country (i.e., products coming from all domestic regions), and international products to represent goods imported from other countries (i.e., the rest of the world internationally).

Within this context, while calculating the welfare gains from trade, we focus on two alternative definitions of autarky. The first one is what we call as the full autarky, with the corresponding notation of $\omega_{r, r}^{j \prime}(f a), \kappa_{r, r}^{j, k \prime}(f a)$ and $W G T_{r}(f a)$, which follows the literature by setting $\omega_{r, r}^{j \prime}(f a)=\kappa_{r, r}^{j, k^{\prime}}(f a)=1$ in Equations 12 and 13. This corresponds to the case in which region $r$ does not import products from any other region, either domestically or internationally.

The second definition deviates from the literature by focusing on international autarky that is defined as the case in which region $r$ imports products from all domestic regions within the same country, but it does not have any international imports. Since international imports are represented by products coming from region $F$, when we shut down international imports in region $r$ for the hypothetical case, the hypothetical home expenditure share of final goods is given by:

$$
\omega_{r, r}^{j \prime}(i a)=\frac{P_{r, r}^{j} C_{r, r}^{j}}{P_{r} C_{r}-P_{r, F}^{j} C_{r, F}^{j}}=\frac{P_{r, r}^{j} C_{r, r}^{j}}{\sum_{i \neq F} \sum_{j} P_{r, i}^{j} C_{r, i}^{j}}
$$

which, according to the second equality, also represents the current home expenditure share of final good $j$ within all domestic products (coming from all domestic regions). Similarly, 
the hypothetical home expenditure share of intermediate inputs is given by:

$$
\kappa_{r, r}^{j, k \prime}(i a)=\frac{P_{r, r}^{k} G_{r, r}^{j, k}}{Q_{r}^{j} G_{r}^{j}-P_{r, F}^{k} G_{r, F}^{j, k}}=\frac{P_{r, r}^{k} G_{r, r}^{j, k}}{\sum_{i \neq F} \sum_{k} P_{r, i}^{k} G_{r, i}^{j, k}}
$$

which, according to the second equality, also represents the current home expenditure share of intermediate input $k$ within all domestic intermediate inputs used in the production of good $j$ in region $r$ (coming from all domestic regions). It is implied that the ratio between the current and hypothetical home expenditure shares on final goods that can be used in Equation 12 is given by:

$$
\frac{\omega_{r, r}^{j}}{\omega_{r, r}^{j \prime}(i a)}=\frac{\sum_{i \neq F} \sum_{j} P_{r, i}^{j} C_{r, i}^{j}}{P_{r} C_{r}}
$$

which also represents the current domestic expenditure share of good $j$ in region $r$ within its overall expenditure. Similarly, the ratio between the current and hypothetical home expenditure shares on intermediate inputs that can be used in Equation 13 is given by:

$$
\frac{\kappa_{r, r}^{j, k}}{\kappa_{r, r}^{j, k \prime}(i a)}=\frac{\sum_{i \neq F} \sum_{k} P_{r, i}^{k} G_{r, i}^{j, k}}{Q_{r}^{j} G_{r}^{j}}
$$

which also represents the current domestic expenditure share of good $k$ used in the production of good $j$ in region $r$ within overall domestic expenditure. We denote the corresponding welfare gains measuring the costs of international autarky by $W G T_{r}(i a)$.

In order to show the contribution of domestic trade to overall welfare gains from trade $W G T_{r}(f a)$, we define the domestic welfare gains from trade as follows:

$$
W G T_{r}(d a)=\frac{W G T_{r}(f a)}{W G T_{r}(i a)}
$$

which can be calculated according to Equation 12 by using the following ratio between the current $\omega_{r, r}^{j}$ and hypothetical $\omega_{r, r}^{j \prime}(d a)$ home expenditure shares on final goods in the case of domestic autarky (that is defined as the case in which region $r$ consumes its own products as well as international imports, but it does not import any products from other domestic regions within the same country):

$$
\frac{\omega_{r, r}^{j}}{\omega_{r, r}^{j \prime}(d a)}=\omega_{r, r}^{j \prime}(i a)=\frac{P_{r, r}^{j} C_{r, r}^{j}}{\sum_{i \neq F} \sum_{j} P_{r, i}^{j} C_{r, i}^{j}}
$$

which is the current home expenditure share of final good $j$ within all domestic products (coming from all domestic regions) as in Equation 14, and the following ratio between the 
current and hypothetical home expenditure shares on intermediate inputs:

$$
\frac{\kappa_{r, r}^{j, k}}{\kappa_{r, r}^{j, k \prime}(d a)}=\kappa_{r, r}^{j, k \prime}(i a)=\frac{P_{r, r}^{k} G_{r, r}^{j, k}}{\sum_{i \neq F} \sum_{k} P_{r, i}^{k} G_{r, i}^{j, k}}
$$

which is the current home expenditure share of intermediate input $k$ within all domestic intermediate inputs used in the production of good $j$ in region $r$ (coming from all domestic regions) as in Equation 15.

According to Equation 17, we can also decompose overall percentage welfare gains from trade $W G T_{r}(f a)$ into domestic percentage welfare gains from trade $W G T_{r}(d a)$ and international percentage welfare gains from trade $W G T_{r}(i a)$ as follows:

$$
\underbrace{\log W G T_{r}(f a)}_{\text {Overall \% WGT }}=\underbrace{\log W G T_{r}(d a)}_{\text {Domestic \% WGT }}+\underbrace{\log W G T_{r}(i a)}_{\text {International \% WGT }}
$$

which can be rewritten as follows for each region $r$ :

$$
1=\frac{\log W G T_{r}(d a)}{\log W G T_{r}(f a)}+\frac{\log W G T_{r}(i a)}{\log W G T_{r}(f a)}
$$

where the first term represents the contribution of domestic welfare gains, while the second term represents the contribution of international welfare gains.

\section{Data and Descriptive Statistics}

Since the calculation of expenditure shares (that are necessary for the determination of domestic and international welfare gains from trade) require data on both domestic and international imports, we focus on the state-level data from the U.S. for the year of 2012. State-level domestic data are from Commodity Flow Survey (CFS) covering bilateral trade across states, including internal trade within each state. ${ }^{2}$ State-level international trade data are from U.S. Census Bureau. ${ }^{3}$ We focus on the combination of these two data sets, which results in the coverage of 19 three-digit NAICS sectors, covering mining (except oil and gas) and manufacturing sectors. The list of these sectors is given in Table 1.

When the complete version of the model is used in order to calculate welfare gains from trade (according to Equation 12), where we need expenditure share information on both final goods and intermediate inputs, following Hillberry and Hummels (2008), we decompose

\footnotetext{
${ }^{2}$ The data can be downloaded at https://www.census.gov/econ/cfs/.

${ }^{3}$ The data can be downloaded at https://usatrade.census.gov/.
} 
overall trade data into final goods and intermediate inputs by using input-output tables for the U.S. for the year of 2012 from Bureau of Economic Analysis. ${ }^{4}$ These tables include information on the use of commodities produced by each NAICS industry and consumed by each NAICS industry as well as personal consumption expenditure; hence, for each destination state, we can identify the share of intermediate inputs consumed by each NAICS industry (and by final consumers given in Table 1) within the overall value of imports coming from a particular source. Once expenditures on final goods and intermediate inputs are identified for each NAICS industry, they are further used to construct region-specific expenditure shares of $\beta_{r}^{j}$ 's and $\kappa_{r, r}^{j, k}$ 's. The input-output tables also provide information on the factor shares of $\gamma^{j, k}$ 's and $g^{j}$ 's across all NAICS sectors, where one minus the latter (i.e., sector-specific labor shares of $l^{j}=1-g^{j}$ 's) are represented in Table 1 .

Finally, using Equation 10, as in Yilmazkuday (2012), we identify the elasticity of substitution $\eta^{j}$ for each NAICS sector by using the very same input-output tables, where the total revenue for good $j$ across all U.S. regions $\sum_{r} Y_{r}^{j} P_{r, r}^{j}$ is calculated as the summation of "intermediate-input expenditure" and "total value added," and the total cost for good $j$ across all U.S. regions $\sum_{r} Y_{r}^{j} Z_{r}^{j}$ is calculated as the summation of "intermediate-input expenditure" and "compensation of employees." The corresponding $\eta^{j}$ measures are given in Table 1, with an average of 5.327 across sectors and a range between 1.385 and 10.229; these values are highly consistent with the estimates of $\eta^{j}$ in the literature (e.g., see the estimates and the literature covered in Yilmazkuday (2012)).

When the number of goods is restricted to one (as shown in Equation 22, below), welfare gains from trade calculations require the aggregate-level measures of $\omega_{r, r}, \kappa_{r, r}, \eta$ and $g$. When intermediate-input trade is shut down by setting $g^{j}=0$ for all $j$ (as shown in Equation 23, below), we need sector-level measures of $\omega_{r, r}^{j}, \beta_{r}^{j}$ and $\eta^{j}$, this time $\omega_{r, r}^{j}$ and $\beta_{r}^{j}$ representing the statistics from the overall trade (rather than just final goods as in the complete case). When the first two restrictions are combined (as shown in Equation 20, below), we need the aggregate-level measures of $\omega_{r, r}$ and $\eta$, where the calculation of $\omega_{r, r}$ in this case considers trade in both final and intermediate-inputs. We calculate all of these statistics from the very same input-output tables introduced above by achieving the necessary aggregations (implied by the details of the model) across our NAICS sectors.

Based on these definitions, Table 2 provides state-level measures of home expenditure share (defined as the expenditure of a state on its own products), foreign expenditure share (defined as the expenditure of a state on products coming from other states) and international expenditure share (defined as the expenditure of a state on products coming from other

\footnotetext{
${ }^{4}$ The corresponding "Use of Commodities by Industries" data are obtained from https://www.bea.gov/industry/io_annual.htm.
} 
countries). As is evident, international expenditure share is only about $17.5 \%$ on average across states with a range between $4.8 \%$ and $35.9 \%$, while the foreign expenditure share is about $60.7 \%$ on average across states with a range between $33.9 \%$ and $83.2 \%$. It is implied that a big portion of a state's expenditure is on the products of other states rather than the state's own products or other international products. Accordingly, we expect to find much bigger welfare gains from trade due to domestic trade (measured by $W G T_{r}(d a)$ ) compared to welfare gains from trade due to international trade (measured by $W G T_{r}(i a)$ ). Nevertheless, such welfare gains from trade also depend on certain model parameters (as we discussed above) that we combine with the corresponding expenditure shares next.

\section{Empirical Results}

Considering its ingredients, we call our complete model (and the corresponding welfare gains from trade given in Equation 12) as the multiple-sector model with input-output linkages or $M S I O$ in short. Within this picture, in order to see the contribution of each model ingredient, we consider several special cases of Equation 12 in the following subsections. We start with providing the results of the most basic model of OSLO (one-sector-labor-only) so that we can explain the contribution of each additional model ingredient with respect to this benchmark case until we finally reach our complete model.

\subsection{One-Sector-Labor-Only (OSLO) Model}

When the number of goods is one (i.e., $\beta_{r}^{j}=\gamma^{j, k}=1, g^{k}=g^{j}=g, \omega_{r, r}^{j}=\omega_{r, r}, \kappa_{r, r}^{j, k}=\kappa_{r, r}$, and $\eta^{j}=\eta^{k}=\eta$ ) and we shut down intermediate input trade by setting $g^{j}=0$ for all $j$, Equation 12 is simplified as:

$$
W G T_{r}=\left(\frac{\omega_{r, r}}{\omega_{r, r}^{\prime}}\right)^{\frac{1}{1-\eta}}
$$

which is the typical expression in the literature (introduced by Arkolakis, Costinot, and Rodríguez-Clare (2012)) when the hypothetical case refers to the full autarky of region $r$ (i.e., $\omega_{r, r}^{\prime}=1$ ) for which we need information on home expenditure share of $\omega_{r, r}$ and the elasticity of substitution $\eta$ (or the trade elasticity $\eta-1$ ). We call this special case as onesector-labor-only model or OSLO in short.

In the OSLO model, welfare gains from trade defined as the costs of full autarky are given by the following expression ( since $\omega_{r, r}^{\prime}(f a)=1$ ):

$$
W G T_{r}(f a)=\left(\omega_{r, r}\right)^{\frac{1}{1-\eta}}
$$


which is the expression introduced by Arkolakis, Costinot, and Rodríguez-Clare (2012), with $n-1$ representing the trade elasticity. According to this expression, overall welfare gains from trade increases with the current overall openness of the region $\left(1-\omega_{r, r}\right)$ and decreases with the trade elasticity of $n-1$ ( $\operatorname{since} \omega_{r, r}<1$ for any open region). Considering $\omega_{r, r}$ values in Table $1, W G T_{r}$ ( $f a$ ) takes its highest (lowest) values for states such as Rhode Island and District of Columbia (Louisiana and Hawaii). The complete set of results are given in Table 3 and Figure 1, where $\log W G T_{r}(f a)$ ranges between 0.242 and 1.154 with an average of 0.635 .

Similarly, welfare gains from trade defined as the costs of international autarky are given by the following expression:

$$
W G T_{r}(i a)=\left(\frac{\omega_{r, r}}{\omega_{r, r}^{\prime}(i a)}\right)^{\frac{1}{1-\eta}}=\left(\omega_{r, r}^{\prime}(d a)\right)^{\frac{1}{1-\eta}}
$$

where international welfare gains from trade increases with the international openness $\left(1-\omega_{r, r}^{\prime}(d a)\right)$ of the region (according to the one-sector version of Equation 16). Considering $\omega_{r, r}^{\prime}(d a)$ values in Table $1, W G T_{r}(i a)$ takes its highest (lowest) values for states such as Rhode Island and New Hampshire (Montana and Wyoming). The complete set of results are given in Table 3 and Figure 1, where $\log W G T_{r}(i a)$ ranges between 0.019 and 1.171 with an average of 0.075 .

Finally, domestic welfare gains from trade are given by the following expression:

$$
W G T_{r}(d a)=\left(\omega_{r, r}^{\prime}(i a)\right)^{\frac{1}{1-\eta}}
$$

where domestic welfare gains from trade increase with the domestic openness $\left(1-\omega_{r, r}^{\prime}(i a)\right)$ of the region (according to the one-sector version of Equation 14). Considering $\omega_{r, r}^{\prime}(i a)$ values in Table $1, W G T_{r}(d a)$ takes its highest (lowest) values for states such as Rhode Island and District of Columbia (Louisiana and Hawaii). The complete set of results are given in Table 3 and Figure 1, where $\log W G T_{r}(d a)$ ranges between 0.193 and 1.087 with an average of 0.560 .

Based on these results, we also calculate the contribution of domestic versus international welfare gains to overall welfare gains according to Equation 19. The corresponding results are also given in Table 3, where, on average across states, about $87.8 \%$ of overall percentage welfare gains from trade are due to domestic trade in the OSLO model, with a range of $74.1 \%$ and $96.2 \%$ across states. 


\subsection{One-Sector Model with Input-Output Linkages (OSIO)}

When the number of goods is one (i.e., $\beta_{r}^{j}=\gamma^{j, k}=1, g^{k}=g^{j}=g, \omega_{r, r}^{j}=\omega_{r, r}, \kappa_{r, r}^{j, k}=\kappa_{r, r}$, and $\eta^{j}=\eta^{k}=\eta$ ) and intermediate-input trade is considered, Equation 12 is simplified to the following expression:

$$
W G T_{r}=\left(\frac{\omega_{r, r}}{\omega_{r, r}^{\prime}}\right)^{\frac{1}{1-\eta}}\left(\frac{\kappa_{r, r}}{\kappa_{r, r}^{\prime}}\right)^{\frac{g}{(1-\eta)(1-g)}}
$$

where home expenditure shares of final goods and intermediate inputs enter separately. In this expression, the elasticity of substitution $\eta$ (or the trade elasticity $\eta-1$ ) and the intermediate input share $g$ in production are the two key parameters. We call this special case as one-sector model with input-output linkages or OSIO in short.

In the OSIO model, welfare gains from trade defined as the costs of full autarky are given by the following expression (since $\omega_{r, r}^{\prime}(f a)=\kappa_{r, r}^{\prime}(f a)=1$ ):

$$
W G T_{r}(f a)=\left(\omega_{r, r}\right)^{\frac{1}{1-\eta}}\left(\kappa_{r, r}\right)^{\frac{g}{(1-\eta)(1-g)}}
$$

where overall welfare gains from trade increases with the current overall openness of the region regarding both final goods $\left(1-\omega_{r, r}\right)$ and intermediate inputs $\left(1-\kappa_{r, r}\right)$. Compared to the OSLO model, this expression has the additional term of $\left(\kappa_{r, r}\right)^{\frac{g}{(1-\eta)(1-g)}}$; nevertheless, due to the input-output linkages, $\omega_{r, r}$ measures may well be different from $\kappa_{r, r}$ measures in this OSIO model. Therefore, the interaction between $\left(\omega_{r, r}\right)^{\frac{1}{1-\eta}}$ and $\left(\kappa_{r, r}\right)^{\frac{g}{(1-\eta)(1-g)}}$ is the key here. The corresponding results are given in Table 3 and Figure 2, where $\log W G T_{r}(f a)$ ranges between 0.923 and 3.574 with an average of 2.054 .

Similarly, welfare gains from trade defined as the costs of international autarky are given by the following expression:

$$
\begin{aligned}
W G T_{r}(i a) & =\left(\frac{\omega_{r, r}}{\omega_{r, r}^{\prime}(i a)}\right)^{\frac{1}{1-\eta}}\left(\frac{\kappa_{r, r}}{\kappa_{r, r}^{\prime}(i a)}\right)^{\frac{g}{(1-\eta)(1-g)}} \\
& =\left(\omega_{r, r}^{\prime}(d a)\right)^{\frac{1}{1-\eta}}\left(\kappa_{r, r}^{\prime}(d a)\right)^{\frac{g}{(1-\eta)(1-g)}}
\end{aligned}
$$

where international welfare gains from trade increases with the international openness measures of $\left(1-\omega_{r, r}^{\prime}(d a)\right)$ and $\left(1-\kappa_{r, r}^{\prime}(d a)\right)$. The results given in Table 3 and Figure 2 suggest that $\log W G T_{r}(i a)$ ranges between 0.067 and 0.518 with an average of 0.238 . 
Finally, domestic welfare gains from trade are given by the following expression:

$$
W G T_{r}(d a)=\left(\omega_{r, r}^{\prime}(i a)\right)^{\frac{1}{1-\eta}}\left(\kappa_{r, r}^{\prime}(i a)\right)^{\frac{g}{(1-\eta)(1-g)}}
$$

where domestic welfare gains from trade increase with the domestic openness measures of $\left(1-\omega_{r, r}^{\prime}(i a)\right)$ and $\left(1-\kappa_{r, r}^{\prime}(i a)\right)$. The results given in Table 3 and Figure 2 suggest that $\log W G T_{r}(d a)$ ranges between 0.783 and 3.428 with an average of 1.816 .

Regarding the contribution of domestic to overall welfare gains, the results in Table 3 suggest that about $88.2 \%$ of overall percentage welfare gains from trade are due to domestic trade in the OSIO model, with a range of $76.2 \%$ and $96.0 \%$ across states.

\subsection{Multiple-Sector-Labor-Only (MSLO) Model}

When we only shut down intermediate input trade by setting $g^{j}=0$ for all $j$, Equation 12 is simplified as:

$$
W G T_{r}=\prod_{j}\left(\frac{\omega_{r, r}^{j}}{\omega_{r, r}^{j \prime}}\right)^{\frac{\beta_{r}^{j}}{1-\eta^{j}}}
$$

where we need information on the good-level home expenditure shares $\omega_{r, r}^{j}$ 's, as well as the elasticity of substitution $\eta$ (or the trade elasticity $\eta-1$ ) and good-specific expenditure share of $\beta_{r}^{j}$ 's. We call this special case as multiple-sector-labor-only model or MSLO in short.

In the OSIO model, welfare gains from trade defined as the costs of full autarky are given by the following expression ( since $\omega_{r, r}^{\prime}(f a)=1$ ):

$$
W G T_{r}(f a)=\prod_{j}\left(\omega_{r, r}^{j}\right)^{\frac{\beta_{r}^{j}}{1-\eta^{j}}}
$$

where overall welfare gains from trade increases with the good-specific current overall openness measures of $\left(1-\omega_{r, r}^{j}\right)$. The corresponding results are given in Table 3 and Figure 3, where $\log W G T_{r}(f a)$ ranges between 0.524 and 6.147 with an average of 1.244 .

Similarly, welfare gains from trade defined as the costs of international autarky are given by the following expression:

$$
W G T_{r}(i a)=\prod_{j}\left(\frac{\omega_{r, r}^{j}}{\omega_{r, r}^{j \prime}(i a)}\right)^{\frac{\beta_{r}^{j}}{1-\eta^{j}}}=\prod_{j}\left(\omega_{r, r}^{j \prime}(d a)\right)^{\frac{\beta_{r}^{j}}{1-\eta^{j}}}
$$


where international welfare gains from trade increases with good-specific international openness measures of $\left(1-\omega_{r, r}^{j \prime}(d a)\right)$. The results given in Table 3 and Figure 3 suggest that $\log W G T_{r}$ (ia) ranges between 0.024 and 0.788 with an average of 0.112 .

Finally, domestic welfare gains from trade are given by the following expression:

$$
W G T_{r}(d a)=\prod_{j}\left(\omega_{r, r}^{j \prime}(i a)\right)^{\frac{\beta_{r}^{j}}{1-\eta^{j}}}
$$

where domestic welfare gains from trade increase with good-specific domestic openness measures of $\left(1-\omega_{r, r}^{j \prime}(i a)\right)$. The results given in Table 3 and Figure 3 suggest that $\log W G T_{r}(d a)$ ranges between 0.441 and 5.360 with an average of 1.132 .

Regarding the contribution of domestic to overall welfare gains, the results in Table 3 suggest that about $90.6 \%$ of overall percentage welfare gains from trade are due to domestic trade in the OSIO model, with a range of $72.0 \%$ and $98.9 \%$ across states.

\subsection{Multiple-Sector Model with Input-Output Linkages (MSIO)}

The complete version of the model, which is the multiple-sector model with input-output linkages (MSIO), has already been introduced above. The corresponding welfare gains are depicted in Table 3 and Figure 4, where $\log W G T_{r}(f a)$ ranges between 3.693 and 24.489 with an average of 7.086, $\log W G T_{r}$ ( $\left.i a\right)$ ranges between 0.091 and 2.399 with an average of 0.408 , and $\log W G T_{r}(d a)$ ranges between 3.227 and 24.281 with an average of 6.678 . Within this picture, about $94.1 \%$ of overall percentage welfare gains from trade are due to domestic trade, with a range of $84.6 \%$ and $99.1 \%$ across states.

\subsection{Comparison across Alternative Models}

When alternative models are compared in Table 3, it is evident that compared to the OSLO model, having input-output linkages or sectoral heterogeneity results in higher welfare gains from trade for any definition of autarky considered. This result is consistent with several studies in the literature such as by Levchenko and Zhang (2014), Caliendo and Parro (2015) and Ossa (2015) who have shown that having more structural models through sectoral heterogeneity or input-output linkages brings higher welfare gains from trade.

Compared to OSLO model, we would like to investigate the reasons behind having higher welfare gains in other model specifications. In particular, we would like to know whether the deviations from the OSLO model are due to different expenditure shares or different model parameters (and thus model specifications) across different states. Accordingly, we investigate 
the OSLO-equivalent elasticity $\eta_{r}^{O S L O}$ measures defined as follows in full, international and domestic autarky cases, respectively:

$$
W G T_{r}^{A M}(f a)=\left(\omega_{r, r}\right)^{\frac{1}{1-\eta_{r}^{O S L O(f a)}}}
$$

and

$$
W G T_{r}^{A M}(i a)=\left(\omega_{r, r}^{\prime}(d a)\right)^{\frac{1}{1-\eta_{r}^{O S L O(i a)}}}
$$

and

$$
W G T_{r}^{A M}(d a)=\left(\omega_{r, r}^{\prime}(i a)\right)^{\frac{1}{1-\eta_{r}^{O S L O(d a)}}}
$$

where the superscript $A M$ stands for alternative models of OSIO, MSLO and MSIO. The objective of this exercise is to figure out whether the deviations from the OSLO model are due to having different OSLO trade openness measures (of $\omega_{r, r}, \omega_{r, r}^{\prime}(d a)$ and $\omega_{r, r}^{\prime}(i a)$ ) or they are due to having different model specifications that would be captured by the deviations of $\eta_{r}^{O S L O}$ measures (that are both state and autarky-definition specific) from our aggregate $\eta$ measure of $\eta=3.612$ (introduced in Table 1). In particular, if $\eta_{r}^{O S L O}<3.612$, there are higher welfare gains from trade due to model specification, and if $\eta_{r}^{O S L O}>3.612$, there are higher welfare gains from trade due to trade openness of the state.

The results of this exercise are given in Table 4 . In all definitions of autarky, $\eta_{r}^{O S L O}$ are below $\eta=3.612$ for all states in both OSIO and MSIO models, suggesting that when inputoutput linkages are considered, the model specifications are responsible for higher welfare gains from trade. However, for the MSLO model, especially for the case of international autarky, there are several states for which $\eta_{r}^{O S L O}>3.612$, implying that their higher welfare gains from trade (with respect to the OSLO model) are due to their trade openness, although there are several other states for which $\eta_{r}^{O S L O}<3.612$, suggesting that their higher welfare gains are due to model specifications. In sum, investigating the reasons behind the deviations from the OSLO model makes a big difference for certain states, which are essential for forming the optimal policy.

Independent of the scale of welfare gains, the results regarding the main focus of this paper, which is the comparison of domestic versus international welfare gains from trade, are very similar across different model specifications as shown in Table 3, where the contribution of domestic trade to overall welfare gains range between $72 \%$ and $99.1 \%$ with an average of about $90 \%$ across all models and states. It is implied that independent of the model considered, the domestic welfare gains are much higher than international welfare gains from trade. 
When we search for the reason behind this result, the basic intuition can be best observed through the OSLO model which implies the following ratio between $\log W G T_{r}(d a)$ and $\log W G T_{r}(f a)$ used in Equation 19 to obtain the results in Table 3:

$$
\frac{\log W G T_{r}(d a)}{\log W G T_{r}(f a)}=\frac{\log \omega_{r, r}^{\prime}(i a)}{\log \omega_{r, r}}
$$

where, as is evident, the trade elasticity measure of $\eta-1$ is effectively eliminated. Hence, the results based on the OSLO model are independent of the trade elasticity measure, and the contribution of domestic trade is directly connected to the ratio of $\log \omega_{r, r}^{\prime}(i a)$ to $\log \omega_{r, r}$. When we plot this ratio against the contribution of domestic trade in Figure 5, we observe the perfect negative correlation between the horizontal and vertical axes. Nevertheless, since sectoral heterogeneity and/or input-output linkages enter into model specifications other than OSLO, the share of domestic welfare gains is not perfectly correlated to the ratio of $\log \omega_{r, r}^{\prime}(i a)$ to $\log \omega_{r, r}$ in these specifications, although the negative correlation is still highly evident across states.

In order to investigate whether geography contributes to the share of domestic welfare gains within overall welfare gains, we further show the ratio of $\log W G T_{r}(d a)$ to $\log W G T_{r}(f a)$ on the U.S. map for alternative model specifications in Figures 6-9. As is evident, independent of the model specification considered, coastal states that have an ocean or Gulf of Mexico coastline (e.g., California, Texas, New York) and coastal states that have a Great Lake coastline (e.g., Michigan, Ohio, Illinois) gain relatively more from international trade, while landlocked states gain relatively more from domestic trade.

This result is consistent with the literature based on how landlockedness may affect international trade of a region/country. For example, studies such as by Limao and Venables (2001) or Irwin and Terviö (2002) have shown that landlocked countries trade about 30 percent less than coastal countries, because transport costs (measured by actual shipment quotes) are about 55 percent higher for landlocked countries compared to coastal countries. According to Figures 6-9, such an observation also holds for the states of the U.S.; we will discuss more about this below.

\section{Implications for the U.S.}

Having the welfare measures at the state level, we would like to know their implications for the U.S. at the aggregate level. Accordingly, considering the utility function in Equation 1 
in a particular state, we define the utility function in the U.S. as follows:

$$
C_{U S}=\prod_{r}\left(C_{r}\right)^{\varphi_{r}}
$$

where $\varphi_{r}=P_{r} C_{r} /\left(\sum_{r} P_{r} C_{r}\right)$ represents the expenditure share of state $r$ within the U.S.. The welfare gains from trade in the U.S. are implied as follows:

$$
W G T_{U S}=\frac{C_{U S}}{C_{U S}^{\prime}}=\prod_{r}\left(\frac{C_{r}}{C_{r}^{\prime}}\right)^{\varphi_{r}}=\prod_{r}\left(W G T_{r}\right)^{\varphi_{r}}
$$

where the last equality is implied by Equation 11. Regarding the decomposition of domestic versus international welfare gains from trade, this expression can be written in log form by using Equation 18 as follows:

$$
\underbrace{\log W G T_{U S}(f a)}_{\text {Overall \% WGT }}=\underbrace{\sum_{r} \varphi_{r} \log \left(W G T_{r}(d a)\right)}_{\text {Domestic \% WGT }}+\underbrace{\sum_{r} \varphi_{r} \log \left(W G T_{r}(i a)\right)}_{\text {International \% WGT }}
$$

where the left hand side represents the overall percentage welfare gains from trade, the first right hand side variable represents domestic welfare gains from trade, and the second right hand side variable represents international welfare gains from trade. Compared to the existing literature that focuses only on the international welfare gains of $\left(\sum_{r} \varphi_{r} \log \left(W G T_{r}(i a)\right)\right)$, our analysis can reveals important information on domestic welfare gains of $\left(\sum_{r} \varphi_{r} \log \left(W G T_{r}(d a)\right)\right)$ that are new in this paper.

We focus on the OSLO model to have simple aggregate-level implications, although the analysis in this section can easily be extended for other model specifications. Accordingly, the empirical results based on the state-level analysis of the OSLO model in Equation 24 show that overall percentage welfare gains from trade of the U.S. are about 0.599 that can be decomposed into domestic percentage welfare gains of 0.509 and international percentage welfare gains of 0.090 .

The international welfare gains from trade for the U.S. can also be calculated using the U.S. level home expenditure share (of 0.793 given in Table 2) and the OSLO $\eta$ measure of $\eta=3.612$ (given in Table 1) according to the OSLO model. The results obtained by U.S. level data correspond to international percentage welfare gains of about 0.089 (as given in Table 3) that are highly comparable to the value (of 0.090) obtained from the weighted aggregation of state-level numbers as shown above. Therefore, one in fact can use the implications of a region-level investigation to have national-level implications for welfare gains from trade. 
Since domestic welfare gains from trade cannot be calculated in the absence of domestic trade data and the implications of a region-level investigation can be used to have nationallevel implications for welfare gains from trade, by using the implications of our model, we would like to propose an approximation for domestic welfare gains from trade in the absence of domestic trade data. In particular, although we have not assumed anything regarding the mobility of labor, preferences, or technology across regions of a country so far, for this particular problem, we can assume that labor, preferences, and technology are perfectly mobile within the U.S. through migration of individuals and diffusion of technology. In such a case, the domestic welfare gains in the OSLO model are implied as follows using the OSLO version of Equations 3 and 14 as well as Equation 21:

$$
\begin{aligned}
\sum_{r} \varphi_{r} \log \left(W G T_{r}(d a)\right) & =\sum_{r} \varphi_{r} \log \left(\frac{P_{r, r} C_{r, r}}{\sum_{i \neq F} P_{r, i}^{j} C_{r, i}^{j}}\right)^{\frac{1}{1-\eta}} \\
& =\sum_{r} \varphi_{r} \log \left(\frac{\tau_{r, r}}{\left(\sum_{i \neq F}\left(\tau_{r, i}\right)^{1-\eta}\right)^{\frac{1}{1-\eta}}}\right)
\end{aligned}
$$

where the second equality is due to labor and technology mobility implying $P_{r, r}=P_{i, i}$ and $\beta_{r, r}=\beta_{r, i}$ for all $r$ and $i$, as well as the OSLO version of trade costs $P_{r, i}=\tau_{r, i} P_{i, i}$. Following studies such as by Anderson and Van Wincoop (2004), if we define trade costs within the U.S. as a function of distance $\tau_{r, i}=\left(d_{r, i}\right)^{\delta}$ where $\delta$ represents distance elasticity of trade costs, we can rewrite this expression as follows:

$$
D E A I=\sum_{r} \varphi_{r} \log \left(W G T_{r}(d a)\right)=\sum_{r} \varphi_{r} \log \left(\frac{\left(d_{r, r}\right)^{\delta}}{\left(\sum_{i \neq F}\left(\left(d_{r, i}\right)^{\delta}\right)^{1-\eta}\right)^{\frac{1}{1-\eta}}}\right)
$$

where we already know $\eta(=3.612)$ and $\varphi_{r}$, while distance measures can easily be found within any country. We call this expression as the Dispersion of Economic Activity Index (DEAI). Therefore, under the assumption of labor, preference and technology mobility within a country, one can obtain a measure of domestic welfare gains from trade when domestic trade data are not available, subject to the determination of $\delta$.

In order to provide guidance for future studies, we would like to find $\delta$ measures that are in line with our measures of domestic percentage welfare gains (of 0.509) obtained from our state-level analysis. We start with using the actual shipment distance measures provided 
by our interstate trade data of CFS (as defined in the data section). CFS provides two alternative measures of distance between states, namely great circle distance and routed distance. The results show that $\delta=0.346$ when great circle distance measures are used and $\delta=0.376$ when routed distance measures are used.

Nevertheless, when domestic trade data are not available, it is not possible to have actual shipment distance measures either. Accordingly, we would like to propose a solution using independent data on distance measures. Specifically, we calculate the great circle distance measures between states by using their latitudes and longitudes obtained from Google Maps. The only issue using such an approach is about the calculation of internal distance measures within each state. Following the literature, we use two alternative methodologies for the calculation of internal distance measures. The first methodology follows Wei (1996) by defining the internal distance as one-quarter of the distance of a state to the nearest state. The second methodology follows Head and Mayer (2000) by defining the internal distance as the square root of the area of a state multiplied by a proportionality factor of $0.376\left(=(2 / 3) \pi^{-0.5}\right)$. The results show that $\delta=0.346$ (exactly the same measure as when the great circle distance measures of CFS are used) when we follow Wei (1996) and $\delta=0.520$ when we follow Head and Mayer (2000).

So far, $\delta$ measures have been calculated using the known expenditure shares $\varphi_{r}$ 's of states within the U.S.. However, even data on $\varphi_{r}$ 's may not be available in certain countries for the calculation of domestic welfare gains through DEAI. In such a case, we also propose an alternative version of DEAI where we set $\varphi_{r}$ as one over the number of states for each $r$. In this case, $\delta$ measures that are consistent with the measured domestic welfare gains within the U.S. are implied as $\delta=0.424$ when CFS great circle distance measures are used, $\delta=0.399$ when CFS routed distance measures are used, $\delta=0.397$ when standard great circle distance measures are used with the internal distance measures of Wei (1996), and $\delta=0.343$ when standard great circle distance measures are used with the internal distance measures of Head and Mayer (2000).

All of these $\delta$ values are highly comparable to the corresponding estimates in the literature; e.g., using CFS data for the year of 2007 with the same trade-costs specification of $\tau_{r, i}=$ $\left(d_{r, i}\right)^{\delta}$, Yilmazkuday (2012) estimates $\delta=0.45$ on average across sectors within the U.S., while Limao and Venables (2001) estimate $\delta=0.38$ using actual shipping company quotes as well as using international trade costs data, again with the same specification of $\tau_{r, i}=\left(d_{r, i}\right)^{\delta}$. Therefore, welfare gains from trade within a country can in fact be approximated by using our proposed measure of DEAI for which the elasticity measures borrowed from the literature can be employed. 


\section{$7 \quad$ Policy Implications}

Since domestic welfare gains from trade increases with current domestic openness of a state and international welfare gains from trade increases with the current international openness of a state, when it comes to optimal policy, it is a matter of comparison between policies toward reducing domestic trade costs versus international trade costs. While domestic trade costs are highly related to transportation technologies/networks as well as infrastructure as advocated in several studies such as by Donaldson (2010), international trade costs are related to the same transportation technologies/networks and infrastructure together with trade agreements as shown in studies such as by Limao and Venables (2001) or Irwin and Terviö (2002).

Since landlocked states have relatively higher welfare gains from domestic trade due to their relatively higher domestic expenditure shares (as shown in Figures 5-9), its is implied that they face relatively higher international trade costs. Considering the fact that about 71 percent of international trade is achieved by water transportation according to the U.S. Census Bureau, landlocked states simply pay higher domestic trade costs (as a part of international trade costs) in order to have their international products delivered after they are cleared at the corresponding U.S. port, while such costs are relatively lower for coastal states. This is also in line with studies such as by Van Leemput (2016) who has shown using Indian state-level data that the share of domestic trade barriers within international trade costs increases with the distance of a state to the closest port.

It is implied that even in the case of free international trade through trade agreements, landlocked states will still pay higher trade costs to have international products delivered. Therefore, independent of the international trade policy, landlocked states will always have relatively lower international expenditure shares and thus relatively lower international welfare gains from trade when domestic prices are similar across regions. Within this picture, one optimal policy may be toward reducing such redistributive effects of landlockedness across states regarding their international trade costs. This may well be achieved within the U.S. by providing more federal government funding for landlocked states to be used for building infrastructure with the objective of minimizing trade costs to the corresponding international U.S. ports.

In sum, international trade policies should be evaluated not only based on the redistributive costs of welfare through distribution of earnings across workers (as in Stolper and Samuelson (1941)) but also based on the implications on the cost of living differences across

regions. The latter is in line with studies such as by Deaton and Muellbauer (1980) or recently in the context of trade by Fajgelbaum and Khandelwal (2014) who show that different groups 
of people face alternative welfare gains from trade based on their income and consumption patterns. On top of these studies, this paper suggests that the distribution of economic activity within a country should also be considered by policy makers with the objective of reducing cost of living differences across regions through integrating landlocked regions with the rest of the world.

Having such infrastructure investment toward reducing domestic trade costs of international products is also essential for the overall U.S. economy, since the U.S. is simply the aggregation of all states, including the landlocked ones. Hence, when landlocked states will have cheaper access to international markets, they will also have higher trade openness which will be reflected in the overall welfare gains of the U.S. from international trade. Within this picture, the ratio of domestic to international welfare gains from trade is an essential metric that can be used as a policy tool, since it basically compares the internal integration of an economy to its international integration with the rest of the world. Accordingly, calculating this metric over time can be used to evaluate policies toward integrating all regions of a country with the rest of the world, which can easily be achieved by combining the standard international welfare gains measures in the literature with the proposed DEAI in this paper through using appropriate elasticity measures over time.

\section{Conclusion}

Based on a rich model that takes into account sectoral heterogeneity and input-output linkages, this paper has shown by using state-level data from the U.S. that domestic welfare gains from trade are much higher than international welfare gains from trade. In particular, the share of domestic welfare gains within the overall welfare gains is about 91 percent on average across states, with a range of between 72 percent and 99 percent depending on the current domestic versus international openness of states.

When the same investigation is replicated at the U.S. level, the corresponding international welfare gains perfectly match with those obtained by the state-level investigation. Hence, national-level welfare gains can be calculated by using the implications of a regionlevel analysis. Considering this, since domestic welfare gains cannot be calculated in the absence of domestic trade data (e.g., interstate trade data as in this paper), based on the details of our region-level model, we propose a Dispersion of Economic Activity Index (DEAI) that can capture the effects of domestic welfare gains from trade using data only on domestic distance and certain elasticity measures. We show that DEAI can perfectly capture the 
effects of domestic welfare gains from trade within the U.S. when great circle distances are combined with the standard measures of elasticity borrowed from the literature.

The calculation of DEAI is also shown to be important for policy makers. In particular, when domestic trade data are not available, the proposed DEAI can be compared with the standard measures of international welfare gains from trade in order to evaluate policies toward integrating the regions of a country with the rest of the world. Having such a policy analysis for a large panel of international countries would be the next step for future research to investigate the roles of domestic versus international integration on the standard of living across countries.

\section{References}

Anderson, J. E., And E. Van Wincoop (2004): "Trade costs," Journal of Economic literature, 42(3), 691-751.

Arkolakis, C., A. Costinot, and A. Rodríguez-Clare (2012): "New trade models, same old gains?," The American Economic Review, 102(1), 94-130.

Armington, P. S. (1969): "A theory of demand for products distinguished by place of production," Staff Papers, 16(1), 159-178.

Bergstrand, J. H., M. Larch, and Y. V. Yotov (2015): "Economic integration agreements, border effects, and distance elasticities in the gravity equation," European Economic Review, 78, 307-327.

Caliendo, L., and F. Parro (2015): "Estimates of the Trade and Welfare Effects of NAFTA.," Review of Economic Studies, 82(1).

Deaton, A., And J. Muellbauer (1980): Economics and consumer behavior. Cambridge university press.

Donaldson, D. (2010): "Railroads of the Raj: Estimating the Impact of Transportation Infrastructure," Working Paper 16487, National Bureau of Economic Research.

Fajgelbaum, P. D., And A. Khandelwal (2014): "Measuring the Unequal Gains from Trade," NBER Working Paper, (w20331).

HeAd, K., And T. Mayer (2000): "Non-Europe: the magnitude and causes of market fragmentation in the EU," Weltwirtschaftliches Archiv, 136(2), 284-314. 
Hillberry, R., And D. Hummels (2008): "Trade responses to geographic frictions: A decomposition using micro-data," European Economic Review, 52(3), 527-550.

Irwin, D. A., AND M. TERVIÖ (2002): "Does trade raise income?: Evidence from the twentieth century," Journal of International Economics, 58(1), 1-18.

Levchenko, A. A., And J. Zhang (2014): "Ricardian productivity differences and the gains from trade," European Economic Review, 65, 45-65.

Limao, N., And A. J. Venables (2001): "Infrastructure, geographical disadvantage, transport costs, and trade," The World Bank Economic Review, 15(3), 451-479.

OssA, R. (2015): "Why trade matters after all," Journal of International Economics, 97(2), 266-277.

Ramondo, N., A. Rodriguez-Clare, and M. Saborio-Rodriguez (2016): "Trade, Domestic Frictions, and Scale Effects," American Economic Review, 106(10), 3159-84.

Stolper, W. F., and P. A. Samuelson (1941): "Protection and real wages," The Review of Economic Studies, 9(1), 58-73.

Tombe, T., And J. Winter (2014): "What's Inside Counts: Migration, Taxes, and the Internal Gains from Trade," Discussion paper, University of Calgary Working Paper, 201328.

VAn Leemput, E. (2016): "A Passage to India: Quantifying Internal and External Barriers to Trade," International Finance Discussion Papers 1185.

WEI, S.-J. (1996): "Intra-National Versus International Trade: How Stubborn are Nations in Global Integration?," NBER Working Paper, (w5531).

YILmAZKUDAY, H. (2012): "Understanding interstate trade patterns," Journal of International Economics, 86(1), 158-166. 
Table 1 - Sector-Specific Measures

\begin{tabular}{|c|c|c|c|c|}
\hline NAICS Sector Code & Description & $\eta$ & Labor Share & Final-Consumption Shares \\
\hline 212 & Mining, except oil and gas & 1.796 & 0.388 & 0.006 \\
\hline $311-312$ & Food and beverage and tobacco products & 3.565 & 0.260 & 0.753 \\
\hline $313-314$ & Textile mills and textile product mills & 7.907 & 0.334 & 0.452 \\
\hline $315-316$ & Apparel and leather and allied products & 10.229 & 0.429 & 0.940 \\
\hline 321 & Wood products & 7.275 & 0.385 & 0.093 \\
\hline 322 & Paper products & 5.914 & 0.262 & 0.224 \\
\hline 323 & Printing and related support activities & 5.270 & 0.504 & 0.582 \\
\hline 324 & Petroleum and coal products & 1.385 & 0.300 & 0.788 \\
\hline 325 & Chemical products & 2.514 & 0.235 & 0.404 \\
\hline 326 & Plastics and rubber products & 5.580 & 0.274 & 0.226 \\
\hline 327 & Nonmetallic mineral products & 4.726 & 0.411 & 0.218 \\
\hline 331 & Primary metals & 6.672 & 0.190 & 0.003 \\
\hline 332 & Fabricated metal products & 6.001 & 0.375 & 0.072 \\
\hline 333 & Machinery & 6.010 & 0.323 & 0.092 \\
\hline 334 & Computer and electronic products & 2.632 & 0.635 & 0.415 \\
\hline 335 & Electrical equipment, appliances, and components & 5.422 & 0.376 & 0.472 \\
\hline 336 & Transportation equipment & 5.887 & 0.239 & 0.486 \\
\hline 337 & Furniture and related products & 8.713 & 0.387 & 0.893 \\
\hline - - - - $339--$ & Miscellaneous manufacturing & $\underline{3.711}$ & 0.525 & $\underline{0.862}$ \\
\hline Average & - & 5.327 & 0.360 & 0.420 \\
\hline Minimum & - & 1.385 & 0.190 & 0.003 \\
\hline Maximum & - & 10.229 & 0.635 & 0.940 \\
\hline Aggregate & One-sector equivalent measure & 3.612 & 0.318 & 0.479 \\
\hline
\end{tabular}

Notes: Sector-specific measures of elasticity of substitution $\eta$, factor share of labor, and final-consumption share have been

calculated using input-output data of "Use of Commodities by Industries" obtained from the U.S. Bureau of Economic Analysis for the year of 2012. Final-consumption share represents the share of products of a particular NAICS sector used as final consumption goods; hence, one minus final-consumption share corresponds to the share of products of a particular NAICS sector used as intermediate inputs. 
Table 2 - State-Specific Measures

\begin{tabular}{|c|c|c|c|c|c|c|}
\hline State & State-Code & Home Share $\left(w_{r, r}\right)$ & Foreign Share & International Share & $w_{r, r}^{\prime}(i a)$ & $w_{r, r}^{\prime}(d a)$ \\
\hline Alabama & $\mathrm{AL}$ & 0.304 & 0.570 & 0.126 & 0.348 & 0.874 \\
\hline Alaska & AK & 0.493 & 0.339 & 0.167 & 0.592 & 0.833 \\
\hline Arizona & $\mathrm{AZ}$ & 0.165 & 0.678 & 0.157 & 0.195 & 0.843 \\
\hline Arkansas & $\mathrm{AR}$ & 0.295 & 0.607 & 0.098 & 0.327 & 0.902 \\
\hline California & $\mathrm{CA}$ & 0.231 & 0.466 & 0.302 & 0.332 & 0.698 \\
\hline Colorado & $\mathrm{CO}$ & 0.239 & 0.631 & 0.131 & 0.275 & 0.869 \\
\hline Connecticut & CT & 0.201 & 0.567 & 0.232 & 0.262 & 0.768 \\
\hline Delaware & $\mathrm{DE}$ & 0.242 & 0.507 & 0.250 & 0.323 & 0.750 \\
\hline District of Columbia & $\mathrm{DC}$ & 0.052 & 0.832 & 0.117 & 0.058 & 0.883 \\
\hline Florida & FL & 0.132 & 0.644 & 0.224 & 0.170 & 0.776 \\
\hline Georgia & GA & 0.136 & 0.641 & 0.223 & 0.175 & 0.777 \\
\hline Hawaii & HI & 0.527 & 0.346 & 0.127 & 0.603 & 0.873 \\
\hline Idaho & ID & 0.146 & 0.641 & 0.213 & 0.186 & 0.787 \\
\hline Illinois & IL & 0.176 & 0.621 & 0.202 & 0.221 & 0.798 \\
\hline Indiana & IN & 0.255 & 0.593 & 0.153 & 0.300 & 0.847 \\
\hline Iowa & IA & 0.259 & 0.652 & 0.089 & 0.285 & 0.911 \\
\hline Kansas & $\mathrm{KS}$ & 0.216 & 0.668 & 0.115 & 0.245 & 0.885 \\
\hline Kentucky & $\mathrm{KY}$ & 0.211 & 0.614 & 0.176 & 0.255 & 0.824 \\
\hline Louisiana & LA & 0.531 & 0.361 & 0.107 & 0.595 & 0.893 \\
\hline Maine & $\mathrm{ME}$ & 0.209 & 0.617 & 0.174 & 0.253 & 0.826 \\
\hline Maryland & MD & 0.082 & 0.684 & 0.234 & 0.107 & 0.766 \\
\hline Massachusetts & MA & 0.127 & 0.636 & 0.237 & 0.167 & 0.763 \\
\hline Michigan & MI & 0.179 & 0.541 & 0.280 & 0.249 & 0.720 \\
\hline Minnesota & MN & 0.217 & 0.623 & 0.160 & 0.258 & 0.840 \\
\hline Mississippi & MS & 0.218 & 0.680 & 0.102 & 0.242 & 0.898 \\
\hline Missouri & MO & 0.242 & 0.654 & 0.104 & 0.270 & 0.896 \\
\hline Montana & MT & 0.393 & 0.543 & 0.065 & 0.420 & 0.935 \\
\hline Nebraska & $\mathrm{NE}$ & 0.215 & 0.707 & 0.077 & 0.233 & 0.923 \\
\hline Nevada & NV & 0.088 & 0.700 & 0.212 & 0.112 & 0.788 \\
\hline New Hampshire & $\mathrm{NH}$ & 0.074 & 0.603 & 0.323 & 0.110 & 0.677 \\
\hline New Jersey & $\mathrm{NJ}$ & 0.119 & 0.564 & 0.317 & 0.174 & 0.683 \\
\hline New Mexico & $\mathrm{NM}$ & 0.222 & 0.701 & 0.077 & 0.240 & 0.923 \\
\hline New York & NY & 0.084 & 0.605 & 0.311 & 0.122 & 0.689 \\
\hline North Carolina & $\mathrm{NC}$ & 0.196 & 0.606 & 0.198 & 0.244 & 0.802 \\
\hline North Dakota & $\mathrm{ND}$ & 0.225 & 0.654 & 0.121 & 0.256 & 0.879 \\
\hline Ohio & $\mathrm{OH}$ & 0.258 & 0.598 & 0.145 & 0.301 & 0.855 \\
\hline Oklahoma & OK & 0.282 & 0.630 & 0.088 & 0.309 & 0.912 \\
\hline Oregon & OR & 0.153 & 0.648 & 0.199 & 0.191 & 0.801 \\
\hline Pennsylvania & $\mathrm{PA}$ & 0.212 & 0.606 & 0.182 & 0.259 & 0.818 \\
\hline Rhode Island & RI & 0.049 & 0.592 & 0.359 & 0.077 & 0.641 \\
\hline South Carolina & $\mathrm{SC}$ & 0.136 & 0.629 & 0.235 & 0.178 & 0.765 \\
\hline South Dakota & $\mathrm{SD}$ & 0.166 & 0.767 & 0.067 & 0.178 & 0.933 \\
\hline Tennessee & $\mathrm{TN}$ & 0.110 & 0.650 & 0.240 & 0.145 & 0.760 \\
\hline Texas & $\mathrm{TX}$ & 0.386 & 0.428 & 0.186 & 0.474 & 0.814 \\
\hline Utah & $\mathrm{UT}$ & 0.214 & 0.649 & 0.137 & 0.248 & 0.863 \\
\hline Vermont & VT & 0.067 & 0.661 & 0.271 & 0.092 & 0.729 \\
\hline Virginia & VA & 0.234 & 0.623 & 0.143 & 0.273 & 0.857 \\
\hline Washington & WA & 0.337 & 0.481 & 0.182 & 0.412 & 0.818 \\
\hline West Virginia & wV & 0.142 & 0.761 & 0.097 & 0.157 & 0.903 \\
\hline Wisconsin & WI & 0.263 & 0.603 & 0.135 & 0.303 & 0.865 \\
\hline Wyoming & WY & $\underline{0 .} \underline{4} \underline{12}$ & $\underline{0.5} \underline{4}$ & -0.048 & 0.433 & -0.952 \\
\hline Average & - & 0.218 & 0.607 & 0.175 & 0.260 & 0.825 \\
\hline Minimum & - & 0.049 & 0.339 & 0.048 & 0.058 & 0.641 \\
\hline Maximum & - & 0.531 & 0.832 & 0.359 & 0.603 & 0.952 \\
\hline United States & US & 0.793 & - & 0.207 & - & - \\
\hline
\end{tabular}

Notes: Home share, foreign share, and int't share represent the expenditure share of the state on its own products, products imported from other states, and products imported from other countries, respectively. 
Table 3 - Percentage Welfare Gains from Trade

\begin{tabular}{|c|c|c|c|c|c|c|c|c|c|c|c|c|}
\hline \multirow[b]{2}{*}{ State } & \multicolumn{4}{|c|}{ Full Autarky } & \multicolumn{4}{|c|}{ International Autarky } & \multicolumn{4}{|c|}{ Domestic over Full Autarky } \\
\hline & OSLO & OSIO & MSLO & MSIO & OSLO & OSIO & MSLO & MSIO & OSLO & OSIO & MSLO & MSIO \\
\hline Alabama & 0.456 & 1.465 & 0.576 & 4.784 & 0.052 & 0.168 & 0.040 & 0.194 & 0.886 & 0.885 & 0.931 & 0.959 \\
\hline Alaska & 0.271 & 1.056 & 1.024 & 7.000 & 0.070 & 0.236 & 0.287 & 0.829 & 0.741 & 0.776 & 0.720 & 0.882 \\
\hline Arizona & 0.690 & 2.150 & 0.949 & 5.566 & 0.065 & 0.207 & 0.066 & 0.199 & 0.905 & 0.904 & 0.931 & 0.964 \\
\hline Arkansas & 0.467 & 1.584 & 0.686 & 5.109 & 0.039 & 0.128 & 0.029 & 0.119 & 0.916 & 0.919 & 0.958 & 0.977 \\
\hline California & 0.561 & 1.843 & 0.741 & 3.693 & 0.138 & 0.438 & 0.153 & 0.466 & 0.754 & 0.762 & 0.793 & 0.874 \\
\hline Colorado & 0.548 & 1.775 & 0.736 & 4.199 & 0.054 & 0.171 & 0.056 & 0.198 & 0.902 & 0.904 & 0.924 & 0.953 \\
\hline Connecticut & 0.614 & 1.951 & 0.953 & 6.881 & 0.101 & 0.316 & 0.123 & 0.577 & 0.836 & 0.838 & 0.871 & 0.916 \\
\hline Delaware & 0.543 & 2.087 & 1.637 & 8.042 & 0.110 & 0.362 & 0.316 & 1.164 & 0.797 & 0.827 & 0.807 & 0.855 \\
\hline District of Columbia & 1.135 & 3.574 & 4.437 & 24.489 & 0.047 & 0.146 & 0.049 & 0.208 & 0.958 & 0.959 & 0.989 & 0.991 \\
\hline Florida & 0.775 & 2.423 & 1.747 & 8.634 & 0.097 & 0.309 & 0.151 & 0.574 & 0.875 & 0.873 & 0.913 & 0.934 \\
\hline Georgia & 0.764 & 2.417 & 0.980 & 6.843 & 0.097 & 0.304 & 0.095 & 0.396 & 0.874 & 0.874 & 0.903 & 0.942 \\
\hline Hawaii & 0.245 & 0.985 & 1.388 & 6.218 & 0.052 & 0.192 & 0.053 & 0.177 & 0.788 & 0.805 & 0.962 & 0.971 \\
\hline Idaho & 0.736 & 2.384 & 2.308 & 14.532 & 0.092 & 0.296 & 0.139 & 0.372 & 0.875 & 0.876 & 0.940 & 0.974 \\
\hline Illinois & 0.665 & 2.154 & 0.902 & 4.962 & 0.087 & 0.280 & 0.097 & 0.360 & 0.870 & 0.870 & 0.893 & 0.927 \\
\hline Indiana & 0.524 & 1.678 & 0.673 & 4.701 & 0.063 & 0.201 & 0.071 & 0.345 & 0.879 & 0.880 & 0.894 & 0.927 \\
\hline Iowa & 0.517 & 1.673 & 0.676 & 5.688 & 0.036 & 0.118 & 0.030 & 0.152 & 0.931 & 0.930 & 0.956 & 0.973 \\
\hline Kansas & 0.586 & 2.034 & 0.938 & 5.372 & 0.047 & 0.152 & 0.045 & 0.162 & 0.920 & 0.925 & 0.952 & 0.970 \\
\hline Kentucky & 0.597 & 1.876 & 1.025 & 5.899 & 0.074 & 0.232 & 0.078 & 0.321 & 0.876 & 0.876 & 0.924 & 0.946 \\
\hline Louisiana & 0.242 & 0.923 & 0.725 & 4.746 & 0.044 & 0.140 & 0.179 & 0.546 & 0.820 & 0.848 & 0.753 & 0.885 \\
\hline Maine & 0.599 & 1.877 & 0.942 & 6.794 & 0.073 & 0.224 & 0.145 & 0.615 & 0.878 & 0.881 & 0.846 & 0.910 \\
\hline Maryland & 0.958 & 3.042 & 1.044 & 6.246 & 0.102 & 0.326 & 0.089 & 0.387 & 0.894 & 0.893 & 0.915 & 0.938 \\
\hline Massachusetts & 0.790 & 2.499 & 1.192 & 6.831 & 0.103 & 0.323 & 0.172 & 0.650 & 0.869 & 0.871 & 0.855 & 0.905 \\
\hline Michigan & 0.658 & 2.058 & 0.524 & 4.671 & 0.126 & 0.392 & 0.084 & 0.354 & 0.809 & 0.810 & 0.841 & 0.924 \\
\hline Minnesota & 0.585 & 1.871 & 0.899 & 5.269 & 0.067 & 0.211 & 0.066 & 0.229 & 0.886 & 0.887 & 0.926 & 0.956 \\
\hline Mississippi & 0.584 & 1.854 & 1.622 & 8.106 & 0.041 & 0.137 & 0.040 & 0.155 & 0.929 & 0.926 & 0.975 & 0.981 \\
\hline Missouri & 0.544 & 1.733 & 1.168 & 7.699 & 0.042 & 0.135 & 0.038 & 0.188 & 0.923 & 0.922 & 0.967 & 0.976 \\
\hline Montana & 0.358 & 1.367 & 0.864 & 5.966 & 0.026 & 0.092 & 0.030 & 0.142 & 0.928 & 0.933 & 0.965 & 0.976 \\
\hline Nebraska & 0.588 & 1.880 & 0.832 & 6.557 & 0.031 & 0.098 & 0.025 & 0.124 & 0.948 & 0.948 & 0.969 & 0.981 \\
\hline Nevada & 0.931 & 2.916 & 1.272 & 5.742 & 0.091 & 0.283 & 0.115 & 0.287 & 0.902 & 0.903 & 0.909 & 0.950 \\
\hline New Hampshire & 0.995 & 2.982 & 6.147 & 21.908 & 0.149 & 0.416 & 0.788 & 2.399 & 0.850 & 0.860 & 0.872 & 0.890 \\
\hline New Jersey & 0.815 & 2.718 & 1.374 & 6.619 & 0.146 & 0.460 & 0.277 & 1.019 & 0.821 & 0.831 & 0.798 & 0.846 \\
\hline New Mexico & 0.577 & 1.959 & 1.389 & 7.146 & 0.031 & 0.110 & 0.030 & 0.091 & 0.946 & 0.944 & 0.978 & 0.987 \\
\hline New York & 0.947 & 2.898 & 1.157 & 6.355 & 0.142 & 0.425 & 0.146 & 0.575 & 0.850 & 0.853 & 0.874 & 0.909 \\
\hline North Carolina & 0.624 & 1.997 & 0.864 & 6.381 & 0.085 & 0.265 & 0.083 & 0.357 & 0.865 & 0.867 & 0.904 & 0.944 \\
\hline North Dakota & 0.572 & 1.862 & 0.850 & 6.131 & 0.049 & 0.157 & 0.062 & 0.325 & 0.914 & 0.915 & 0.927 & 0.947 \\
\hline Ohio & 0.519 & 1.658 & 0.586 & 4.472 & 0.060 & 0.189 & 0.050 & 0.236 & 0.885 & 0.886 & 0.914 & 0.947 \\
\hline Oklahoma & 0.485 & 1.587 & 0.704 & 5.187 & 0.035 & 0.116 & 0.032 & 0.117 & 0.927 & 0.927 & 0.955 & 0.977 \\
\hline Oregon & 0.718 & 2.247 & 0.996 & 5.876 & 0.085 & 0.270 & 0.077 & 0.330 & 0.882 & 0.880 & 0.922 & 0.944 \\
\hline Pennsylvania & 0.594 & 1.881 & 0.811 & 5.120 & 0.077 & 0.244 & 0.090 & 0.382 & 0.870 & 0.870 & 0.888 & 0.925 \\
\hline Rhode Island & 1.154 & 3.562 & 2.323 & 11.706 & 0.171 & 0.518 & 0.299 & 1.113 & 0.852 & 0.855 & 0.871 & 0.905 \\
\hline South Carolina & 0.764 & 2.395 & 0.941 & 7.177 & 0.103 & 0.321 & 0.103 & 0.462 & 0.866 & 0.866 & 0.891 & 0.936 \\
\hline South Dakota & 0.687 & 2.160 & 1.516 & 8.630 & 0.026 & 0.086 & 0.024 & 0.114 & 0.962 & 0.960 & 0.984 & 0.987 \\
\hline Tennessee & 0.844 & 2.679 & 1.078 & 5.664 & 0.105 & 0.330 & 0.113 & 0.410 & 0.876 & 0.877 & 0.895 & 0.928 \\
\hline Texas & 0.365 & 1.237 & 0.750 & 3.850 & 0.079 & 0.259 & 0.127 & 0.390 & 0.784 & 0.790 & 0.830 & 0.899 \\
\hline Utah & 0.591 & 1.983 & 0.906 & 5.065 & 0.056 & 0.182 & 0.037 & 0.138 & 0.905 & 0.908 & 0.959 & 0.973 \\
\hline Vermont & 1.033 & 3.281 & 2.121 & 8.320 & 0.121 & 0.371 & 0.240 & 0.787 & 0.883 & 0.887 & 0.887 & 0.905 \\
\hline Virginia & 0.556 & 1.876 & 0.822 & 6.002 & 0.059 & 0.191 & 0.059 & 0.282 & 0.893 & 0.898 & 0.928 & 0.953 \\
\hline Washington & 0.416 & 1.386 & 0.590 & 4.416 & 0.077 & 0.244 & 0.075 & 0.286 & 0.815 & 0.824 & 0.872 & 0.935 \\
\hline West Virginia & 0.748 & 2.436 & 2.574 & 13.262 & 0.039 & 0.123 & 0.043 & 0.197 & 0.948 & 0.949 & 0.983 & 0.985 \\
\hline Wisconsin & 0.512 & 1.602 & 0.576 & 5.084 & 0.055 & 0.172 & 0.043 & 0.190 & 0.892 & 0.892 & 0.926 & 0.963 \\
\hline Wyoming & 0.340 & $\begin{array}{l}1.258 \\
---\end{array}$ & $\begin{array}{r}0.908 \\
--ー-ー\end{array}$ & 5.759 & $\begin{array}{c}0.019 \\
---1\end{array}$ & 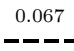 & $\begin{array}{c}0.028 \\
----\end{array}$ & $\begin{array}{l}0.109 \\
---1\end{array}$ & $\underline{0.94} \underline{4}$ & -0.947 & 0.970 & _. \\
\hline Average & 0.635 & 2.054 & 1.244 & 7.086 & 0.075 & 0.238 & 0.112 & 0.408 & 0.878 & 0.882 & 0.906 & 0.941 \\
\hline Minimum & 0.242 & 0.923 & 0.524 & 3.693 & 0.019 & 0.067 & 0.024 & 0.091 & 0.741 & 0.762 & 0.720 & 0.846 \\
\hline Maximum & 1.154 & 3.574 & 6.147 & 24.489 & 0.171 & 0.518 & 0.788 & 2.399 & 0.962 & 0.960 & 0.989 & 0.991 \\
\hline United States & - & - & - & - & 0.089 & 0.281 & 0.177 & 0.384 & - & - & - & - \\
\hline
\end{tabular}


Table 4 - OSLO-Equivalent Elasticity $\eta$ Measures

\begin{tabular}{|c|c|c|c|c|c|c|c|c|c|}
\hline \multirow[b]{2}{*}{ State } & \multicolumn{3}{|c|}{ Full Autarky } & \multicolumn{3}{|c|}{ International Autarky } & \multicolumn{3}{|c|}{ Domestic Autarky } \\
\hline & OSIO & MSLO & MSIO & OSIO & MSLO & MSIO & OSIO & MSLO & MSIC \\
\hline Alabama & 1.813 & 3.069 & 1.249 & 1.804 & 4.398 & 1.697 & 1.814 & 2.970 & 1.230 \\
\hline Alaska & 1.669 & 1.690 & 1.101 & 1.774 & 1.637 & 1.221 & 1.638 & 1.711 & 1.085 \\
\hline Arizona & 1.839 & 2.900 & 1.324 & 1.824 & 3.588 & 1.859 & 1.840 & 2.849 & 1.304 \\
\hline Arkansas & 1.770 & 2.777 & 1.239 & 1.801 & 4.539 & 1.868 & 1.767 & 2.699 & 1.224 \\
\hline California & 1.794 & 2.975 & 1.396 & 1.822 & 3.346 & 1.773 & 1.786 & 2.878 & 1.342 \\
\hline Colorado & 1.807 & 2.946 & 1.341 & 1.820 & 3.505 & 1.705 & 1.806 & 2.900 & 1.323 \\
\hline Connecticut & 1.822 & 2.683 & 1.233 & 1.832 & 3.137 & 1.457 & 1.820 & 2.616 & 1.213 \\
\hline Delaware & 1.679 & 1.865 & 1.176 & 1.796 & 1.913 & 1.248 & 1.654 & 1.854 & 1.164 \\
\hline District of Columbia & 1.829 & 1.668 & 1.121 & 1.847 & 3.526 & 1.595 & 1.829 & 1.647 & 1.117 \\
\hline Florida & 1.835 & 2.158 & 1.234 & 1.821 & 2.676 & 1.441 & 1.837 & 2.109 & 1.220 \\
\hline Georgia & 1.825 & 3.035 & 1.291 & 1.830 & 3.648 & 1.636 & 1.825 & 2.969 & 1.270 \\
\hline Hawaii & 1.651 & 1.462 & 1.103 & 1.705 & 3.570 & 1.765 & 1.637 & 1.378 & 1.084 \\
\hline Idaho & 1.806 & 1.833 & 1.132 & 1.810 & 2.726 & 1.644 & 1.806 & 1.776 & 1.119 \\
\hline Illinois & 1.806 & 2.926 & 1.350 & 1.810 & 3.335 & 1.628 & 1.806 & 2.877 & 1.328 \\
\hline Indiana & 1.815 & 3.034 & 1.291 & 1.825 & 3.326 & 1.480 & 1.814 & 3.000 & 1.276 \\
\hline Iowa & 1.806 & 2.996 & 1.237 & 1.788 & 4.127 & 1.611 & 1.808 & 2.944 & 1.227 \\
\hline Kansas & 1.753 & 2.631 & 1.285 & 1.807 & 3.710 & 1.759 & 1.748 & 2.577 & 1.270 \\
\hline Kentucky & 1.830 & 2.520 & 1.264 & 1.834 & 3.487 & 1.603 & 1.830 & 2.441 & 1.245 \\
\hline Louisiana & 1.686 & 1.872 & 1.133 & 1.812 & 1.635 & 1.208 & 1.663 & 1.950 & 1.124 \\
\hline Maine & 1.834 & 2.662 & 1.230 & 1.854 & 2.320 & 1.312 & 1.831 & 2.724 & 1.222 \\
\hline Maryland & 1.822 & 3.396 & 1.401 & 1.816 & 4.003 & 1.687 & 1.823 & 3.339 & 1.382 \\
\hline Massachusetts & 1.825 & 2.730 & 1.302 & 1.836 & 2.568 & 1.416 & 1.824 & 2.758 & 1.290 \\
\hline Michigan & 1.835 & 4.277 & 1.368 & 1.838 & 4.930 & 1.926 & 1.834 & 4.154 & 1.322 \\
\hline Minnesota & 1.816 & 2.699 & 1.290 & 1.824 & 3.624 & 1.759 & 1.815 & 2.625 & 1.269 \\
\hline Mississippi & 1.823 & 1.940 & 1.188 & 1.788 & 3.688 & 1.693 & 1.825 & 1.896 & 1.178 \\
\hline Missouri & 1.819 & 2.216 & 1.184 & 1.815 & 3.881 & 1.584 & 1.820 & 2.160 & 1.174 \\
\hline Montana & 1.684 & 2.082 & 1.157 & 1.730 & 3.246 & 1.472 & 1.681 & 2.041 & 1.149 \\
\hline Nebraska & 1.817 & 2.846 & 1.234 & 1.817 & 4.157 & 1.650 & 1.816 & 2.805 & 1.226 \\
\hline Nevada & 1.834 & 2.912 & 1.424 & 1.840 & 3.064 & 1.830 & 1.833 & 2.896 & 1.402 \\
\hline New Hampshire & 1.871 & 1.423 & 1.119 & 1.936 & 1.494 & 1.162 & 1.861 & 1.412 & 1.113 \\
\hline New Jersey & 1.784 & 2.550 & 1.322 & 1.830 & 2.377 & 1.375 & 1.774 & 2.594 & 1.312 \\
\hline New Mexico & 1.769 & 2.085 & 1.211 & 1.732 & 3.652 & 1.882 & 1.771 & 2.049 & 1.202 \\
\hline New York & 1.853 & 3.138 & 1.389 & 1.876 & 3.553 & 1.646 & 1.849 & 3.078 & 1.363 \\
\hline North Carolina & 1.817 & 2.887 & 1.256 & 1.834 & 3.655 & 1.618 & 1.814 & 2.805 & 1.234 \\
\hline North Dakota & 1.802 & 2.758 & 1.244 & 1.820 & 3.078 & 1.397 & 1.800 & 2.732 & 1.235 \\
\hline Ohio & 1.818 & 3.316 & 1.303 & 1.830 & 4.118 & 1.662 & 1.816 & 3.240 & 1.283 \\
\hline Oklahoma & 1.798 & 2.798 & 1.244 & 1.795 & 3.925 & 1.786 & 1.798 & 2.745 & 1.231 \\
\hline Oregon & 1.834 & 2.883 & 1.319 & 1.822 & 3.872 & 1.672 & 1.836 & 2.800 & 1.298 \\
\hline Pennsylvania & 1.825 & 2.915 & 1.303 & 1.825 & 3.226 & 1.526 & 1.825 & 2.876 & 1.285 \\
\hline Rhode Island & 1.846 & 2.298 & 1.258 & 1.860 & 2.487 & 1.400 & 1.844 & 2.270 & 1.243 \\
\hline South Carolina & 1.833 & 3.120 & 1.278 & 1.835 & 3.609 & 1.580 & 1.833 & 3.061 & 1.257 \\
\hline South Dakota & 1.830 & 2.182 & 1.208 & 1.803 & 3.865 & 1.604 & 1.831 & 2.155 & 1.202 \\
\hline Tennessee & 1.823 & 3.045 & 1.389 & 1.830 & 3.416 & 1.667 & 1.822 & 3.002 & 1.367 \\
\hline Texas & 1.770 & 2.272 & 1.248 & 1.794 & 2.620 & 1.529 & 1.764 & 2.200 & 1.216 \\
\hline Utah & 1.778 & 2.703 & 1.304 & 1.809 & 4.958 & 2.063 & 1.774 & 2.607 & 1.283 \\
\hline Vermont & 1.823 & 2.273 & 1.324 & 1.854 & 2.318 & 1.402 & 1.819 & 2.267 & 1.316 \\
\hline Virginia & 1.775 & 2.768 & 1.242 & 1.813 & 3.604 & 1.549 & 1.770 & 2.703 & 1.227 \\
\hline Washington & 1.784 & 2.840 & 1.246 & 1.823 & 3.662 & 1.701 & 1.775 & 2.720 & 1.214 \\
\hline West Virginia & 1.802 & 1.759 & 1.147 & 1.830 & 3.397 & 1.519 & 1.800 & 1.731 & 1.142 \\
\hline Wisconsin & 1.835 & 3.321 & 1.263 & 1.840 & 4.381 & 1.761 & 1.834 & 3.236 & 1.244 \\
\hline Wyoming & 1.705 & 1.977 & 1.154 & 1.740 & 2.797 & 1.453 & -1.703 & 1.951 & 1.148 \\
\hline Average & 1.798 & 2.590 & 1.256 & 1.817 & 3.360 & 1.598 & 1.795 & 2.545 & 1.239 \\
\hline Minimum & 1.651 & 1.423 & 1.101 & 1.705 & 1.494 & 1.162 & 1.637 & 1.378 & 1.084 \\
\hline Maximum & 1.871 & 4.277 & 1.424 & 1.936 & 4.958 & 2.063 & 1.861 & 4.154 & 1.402 \\
\hline United States & - & - & - & 1.826 & 2.311 & 1.604 & - & - & - \\
\hline
\end{tabular}


Figure 1 - One-Sector-Labor-Only Model (OSLO)

Domestic versus International Welfare Gains from Trade

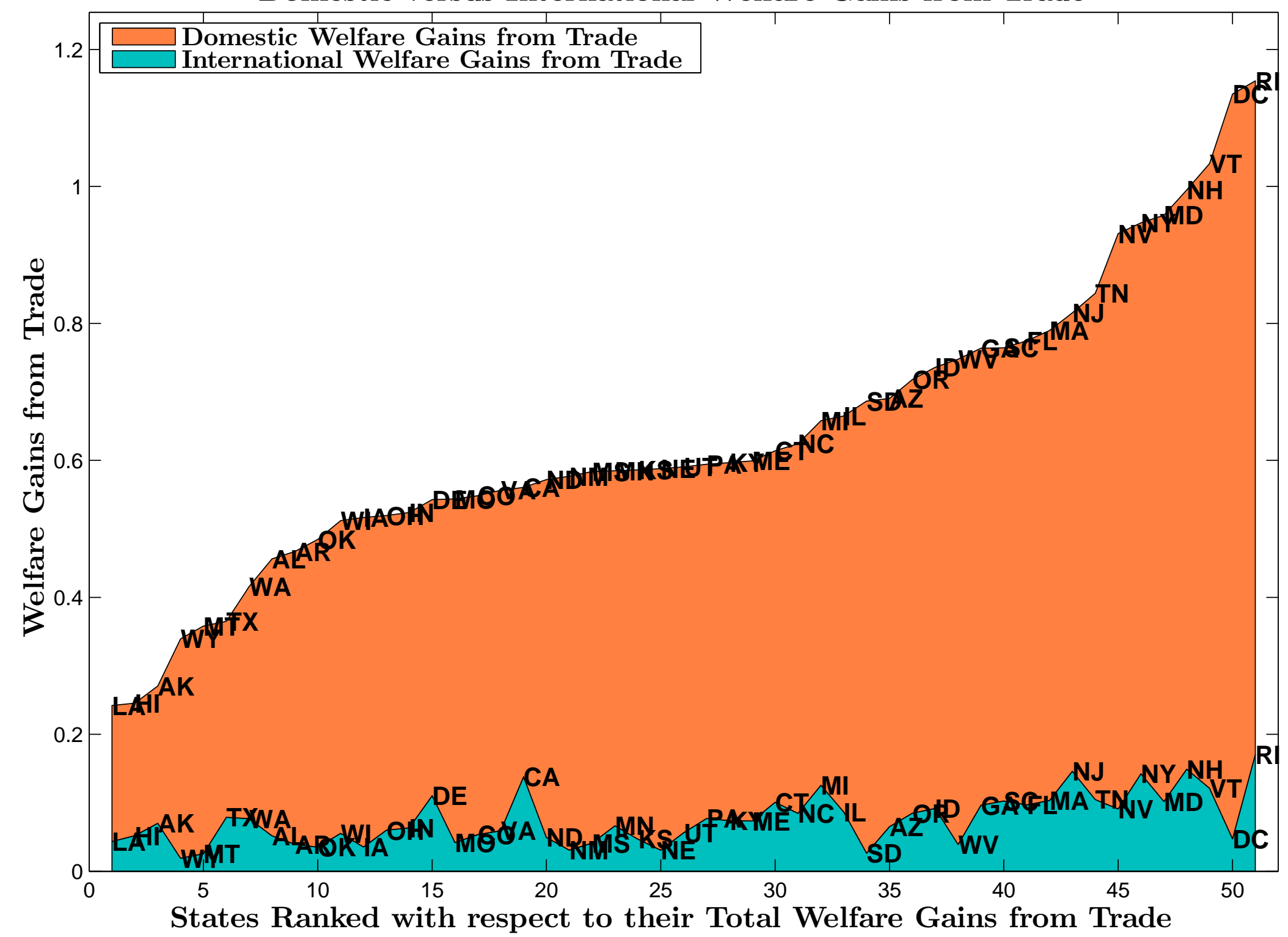


Figure 2 - One-Sector Model with Input-Output Linkages (OSIO)

Domestic versus International Welfare Gains from Trade

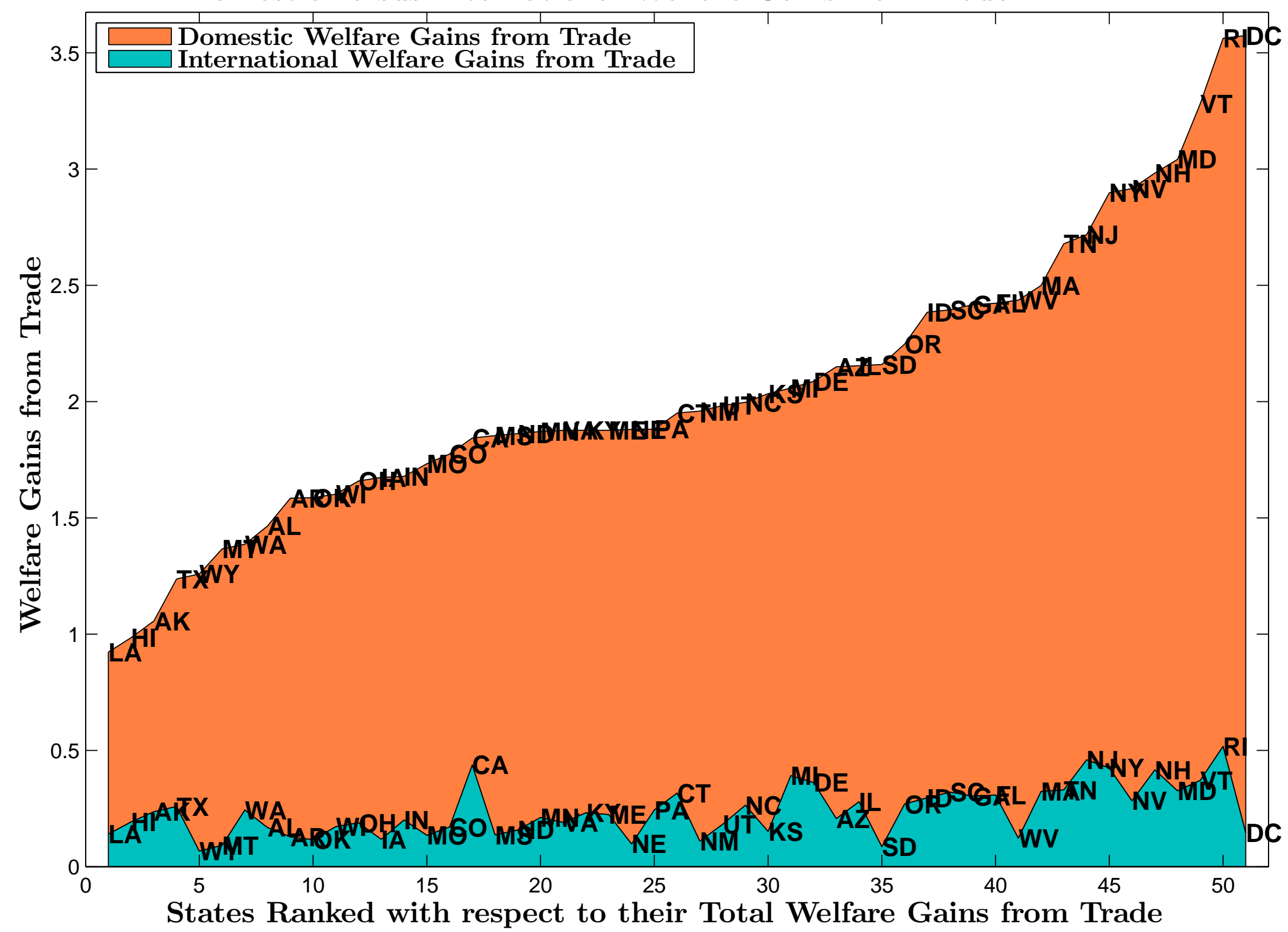


Figure 3 - Multiple-Sector-Labor-Only Model (MSLO)

Domestic versus International Welfare Gains from Trade

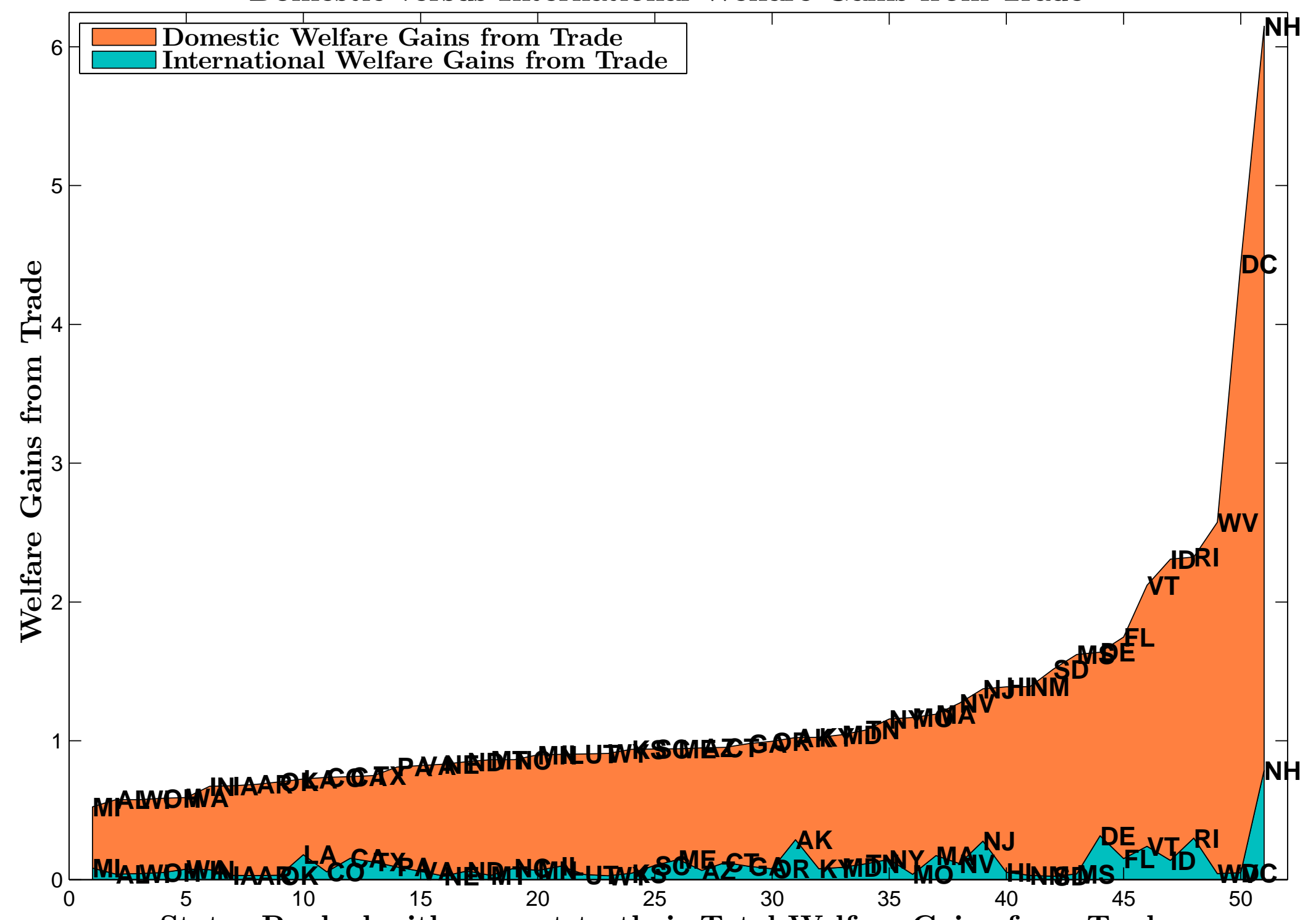

States Ranked with respect to their Total Welfare Gains from Trade 
Figure 4 - Multiple-Sector Model with Input-Output Linkages (MSIO)

Domestic versus International Welfare Gains from Trade

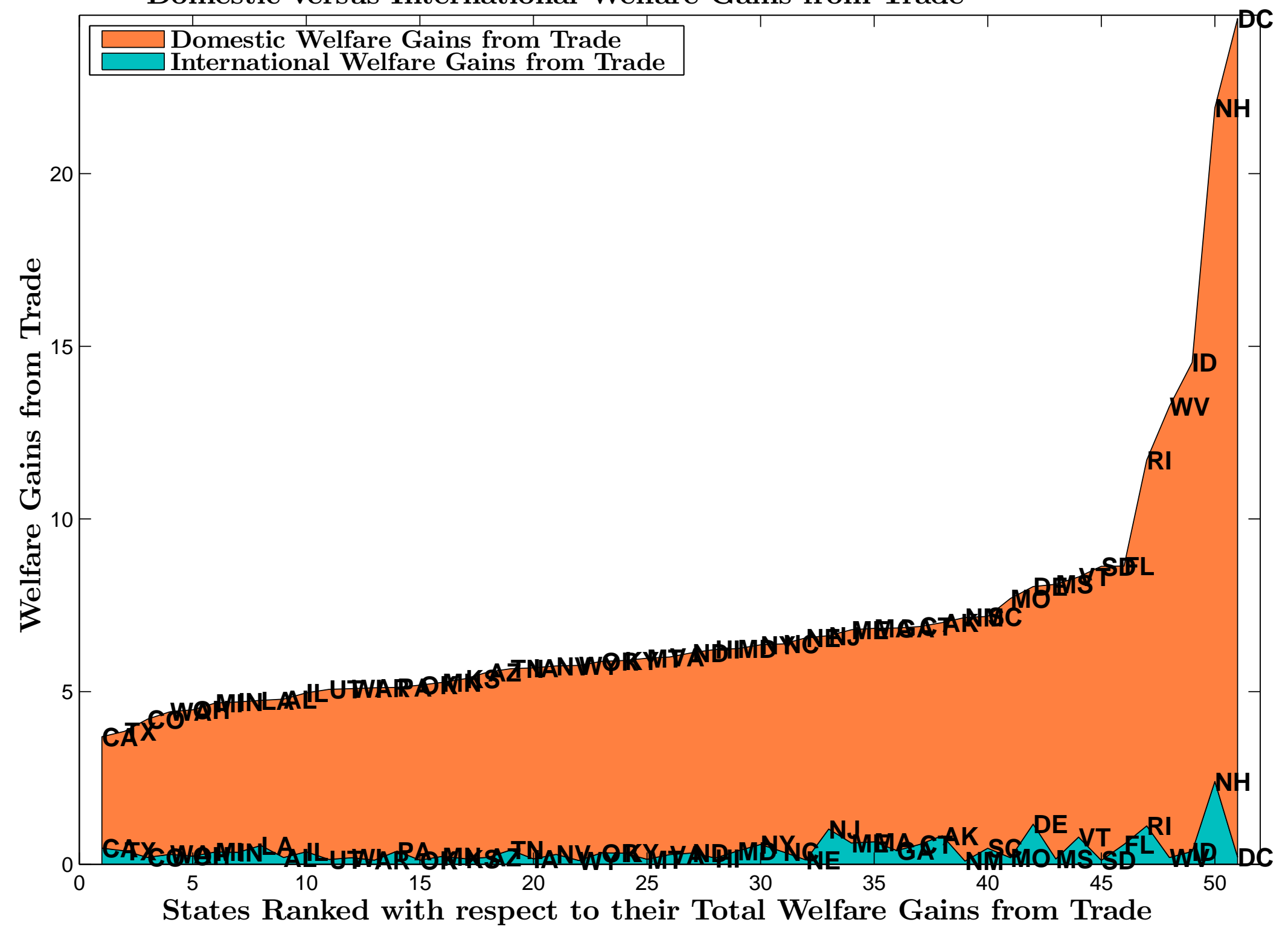


Figure 5 - Comparison across Alternative Models

Share of Domestic Welfare Gains in Overall Welfare Gains

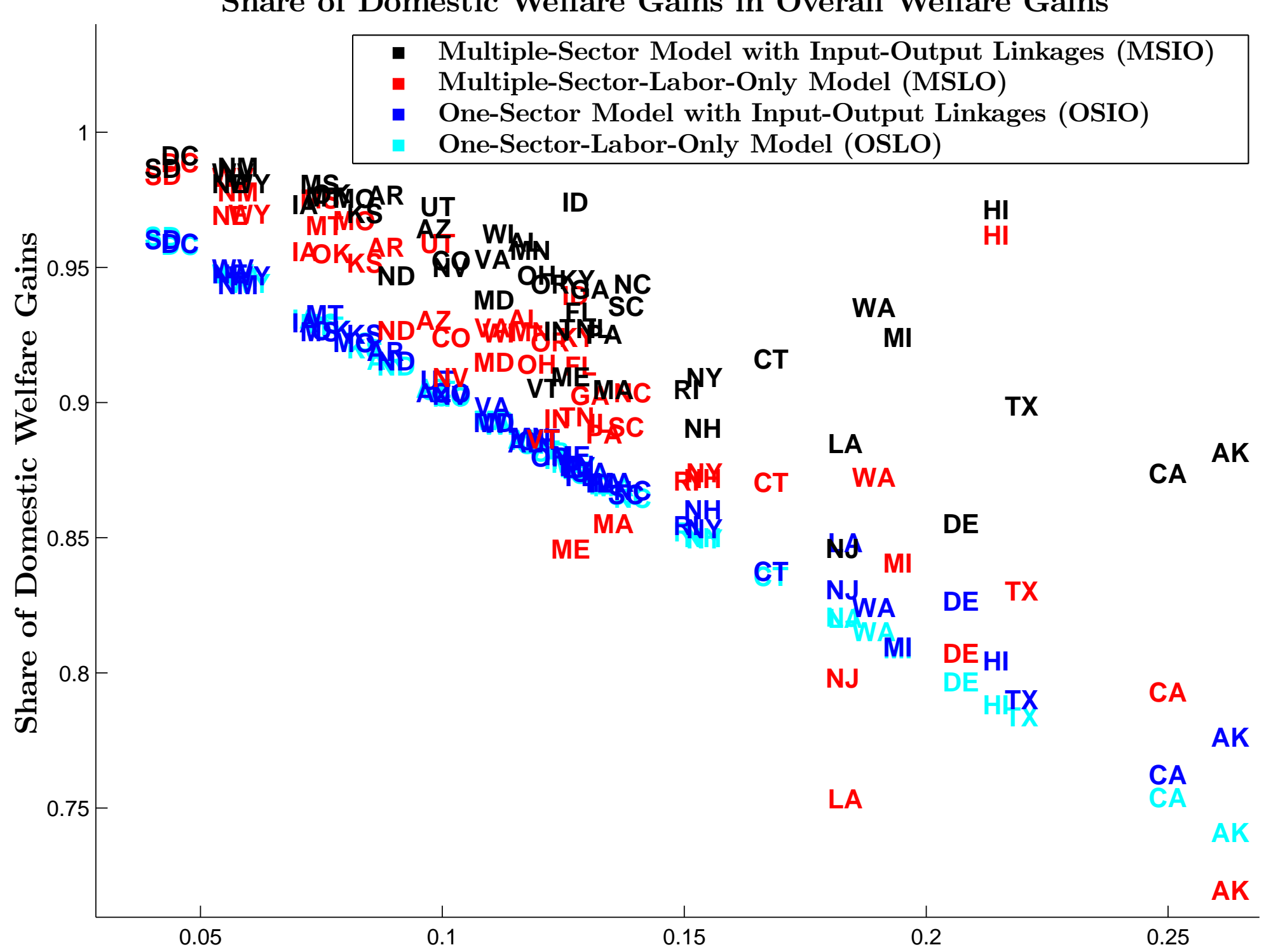

Log Domestic Home Exp. Share over Log Overall Home Exp. Share 
Figure 6 - Domestic versus Overall Welfare Gains from Trade

One-Sector-Labor-Only Model (OSLO)
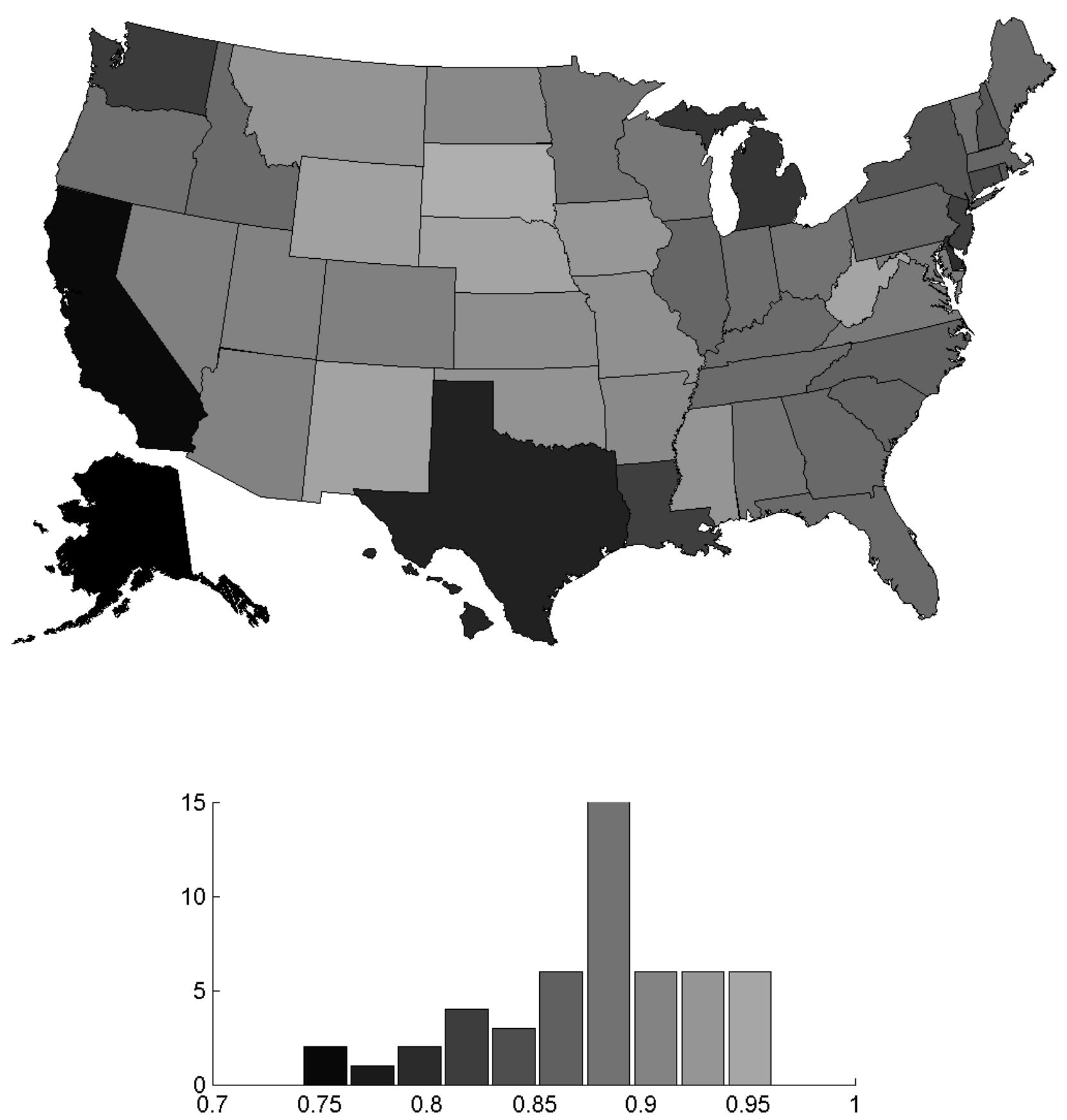

Notes: The values show the domestic over overall percentage welfare gains from trade in Table 3. 
Figure 7 - Domestic versus Overall Welfare Gains from Trade One-Sector Model with Input-Output Linkages (OSIO)
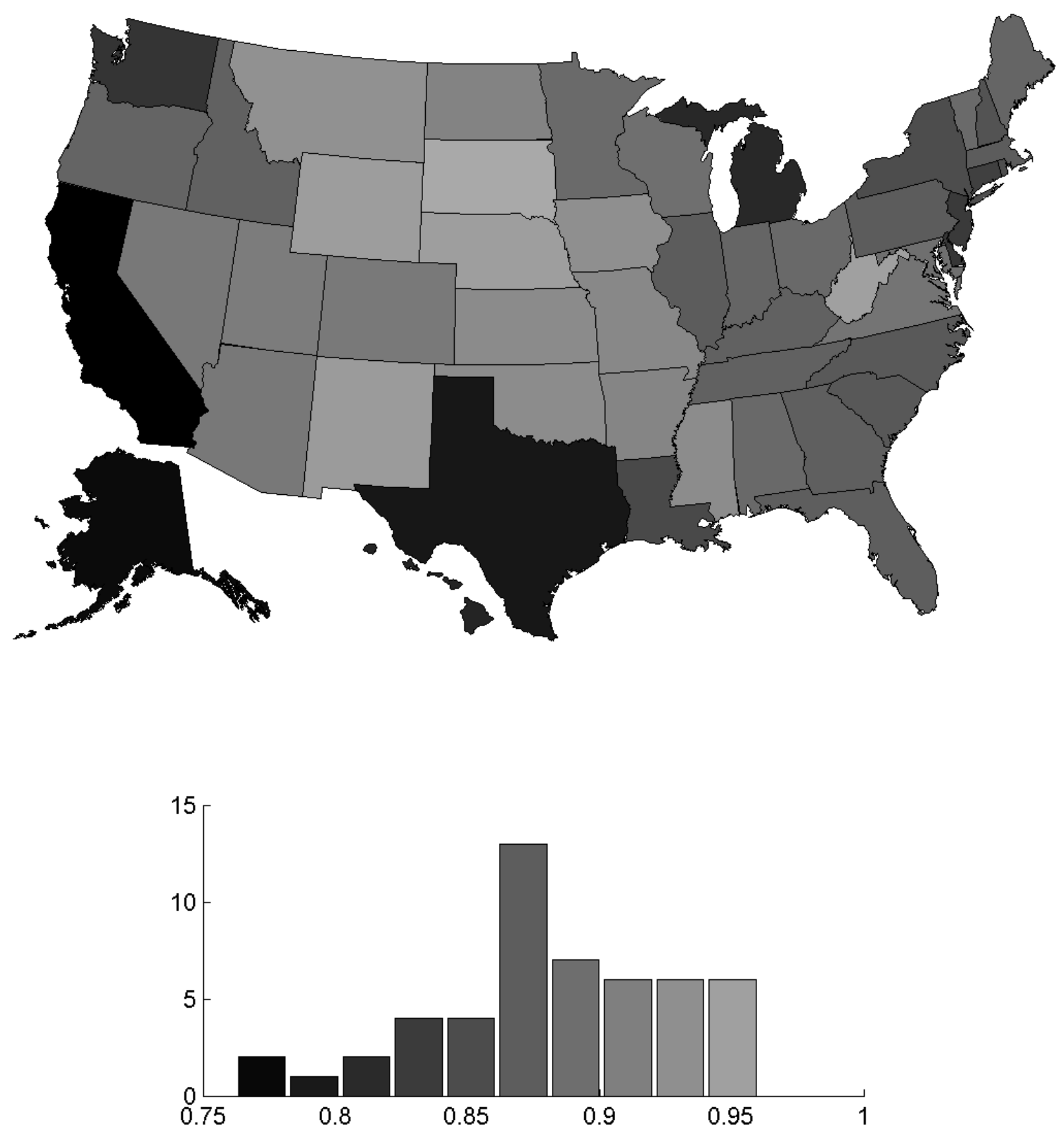

Notes: The values show the domestic over overall percentage welfare gains from trade in Table 3. 
Figure 8 - Domestic versus Overall Welfare Gains from Trade

Multiple-Sector-Labor-Only Model (MSLO)
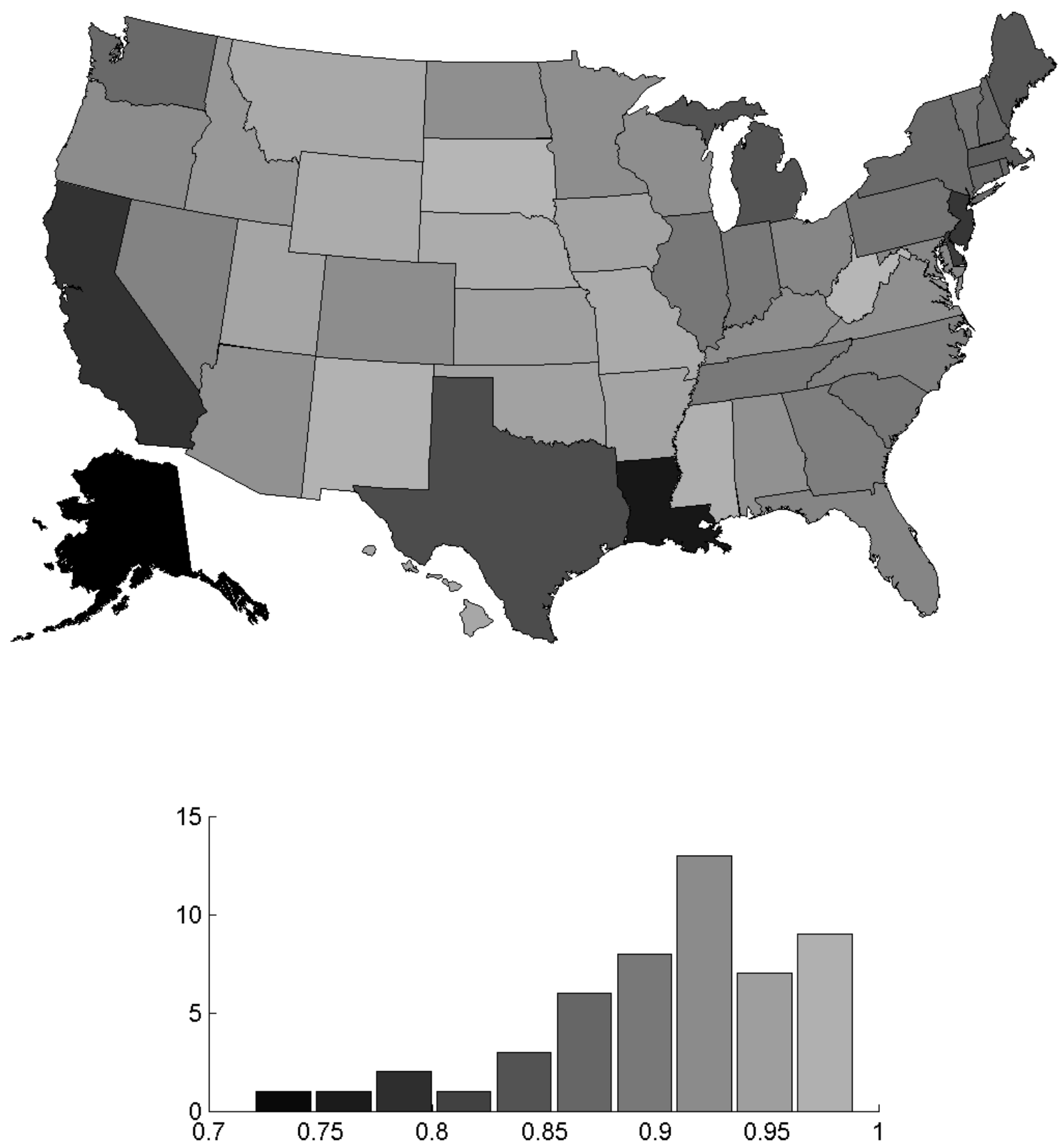

Notes: The values show the domestic over overall percentage welfare gains from trade in Table 3. 
Figure 9 - Domestic versus Overall Welfare Gains from Trade Multiple-Sector Model with Input-Output Linkages (MSIO)
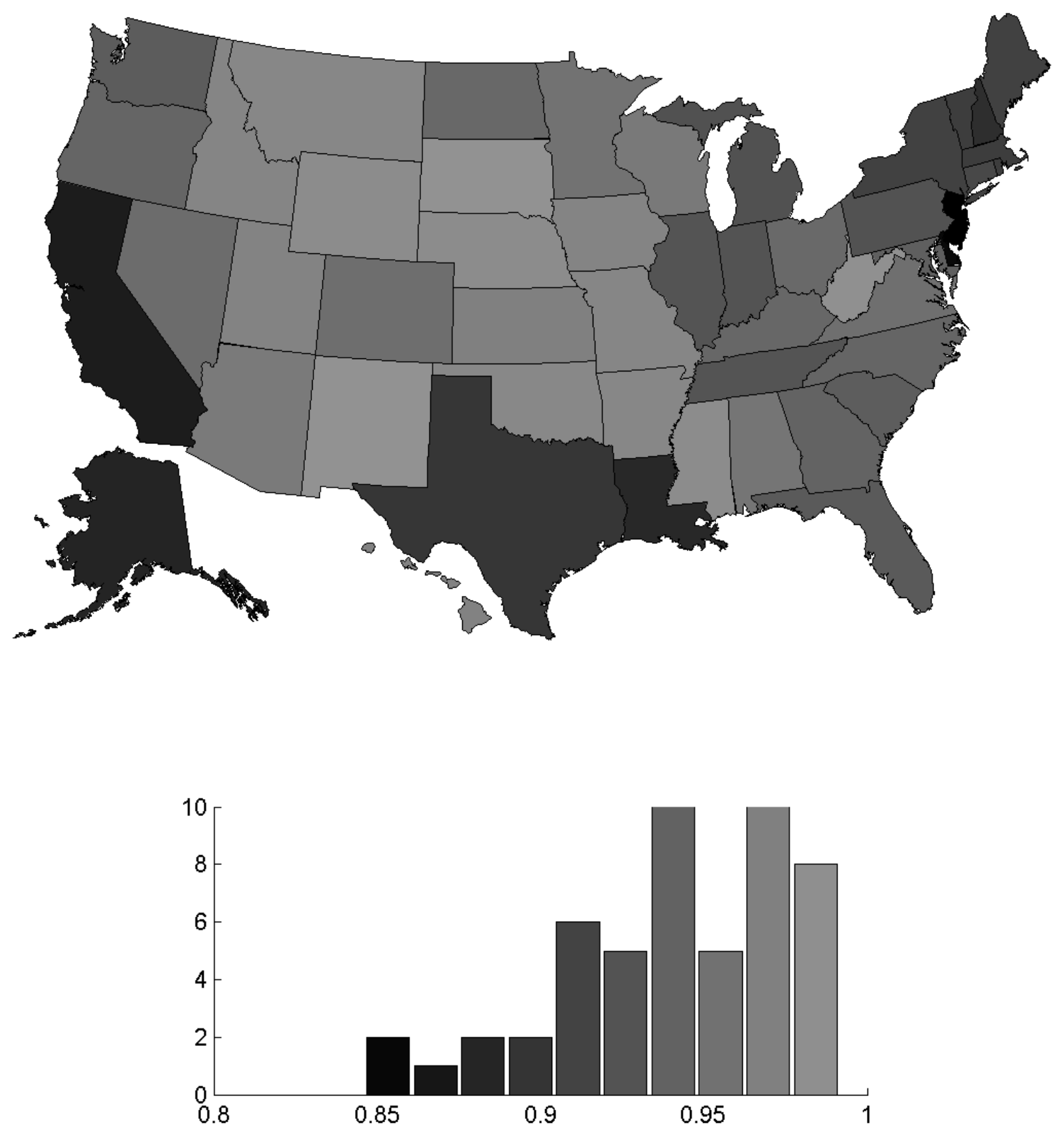

Notes: The values show the domestic over overall percentage welfare gains from trade in Table 3. 